\title{
Charisma: An ill-defined and ill-measured gift
}

\author{
John Antonakis \\ $\&$ \\ Nicolas Bastardoz \\ Department of Organizational Behavior \\ University of Lausanne \\ john.antonakis@unil.ch \\ Philippe Jacquart \\ EMLYON Business School \\ jacquart@em-lyon.com \\ Boas Shamir \\ Department of Sociology and Anthropology \\ The Hebrew University of Jerusalem
}

In press:

\section{Annual Review of Organizational Psychology and Organizational Behavior}

"Posted with permission from the Annual Review of Organizational Psychology and Organizational Behavior, Volume 3 (c) 2016 by Annual Reviews, http://www.annualreviews.org."

Note: Sadly, Boas passed away before this article could be completed. In consultation with the editorial team at the Annual Reviews, we added Boas posthumously in the author list. Boas significantly contributed to what we planned to write, he extensively commented on the coding procedure we used, and we had several discussions with him about the content and direction of the article. We thank Laurent Lehmann, Thomas von Ungern-Sternberg, and Christian Zehnder for helpful comments they provided us during the development of this manuscript. We are also very grateful to Manon Jaquerod and Sirio Lonati for their assistance in coding the articles. 


\begin{abstract}
We take historical stock of charisma, tracing its origins and how it has been conceptualized in the sociological and organizational sciences literatures. Although charisma has been intensely studied, the concept is still not well understood and much of the research undertaken cannot inform policy. We show that the major obstacles to advancing our understanding of charisma have included issues with its definition, its confusion with transformational leadership, the use of questionnaire measures, and that it has not been studied using correctly-specified causal models. To help spawn a new genre of research in charisma, we use signaling theory to provide a general definition of charisma, and make suggestions about how charisma should be conceptualized, operationalized, and modeled. We also describe trends and patterns in articles we reviewed, using co-citation as well as bibliometric analyses, and discuss the practical implications of our findings.
\end{abstract}

Keywords: charismatic leadership, signaling theory, endogeneity, causality, leader development. 


\section{Contents}

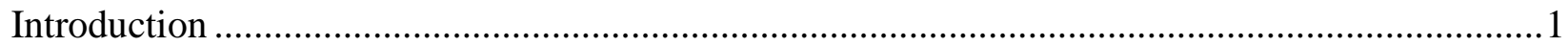

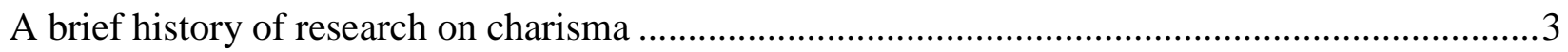

The foundations: Sociology and political science ............................................................4

The edifice: Applied psychology and management ...................................................... 8

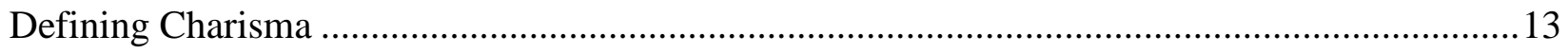

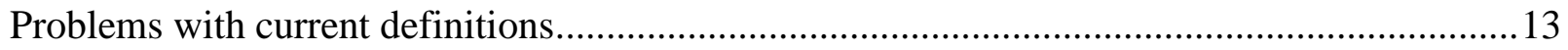

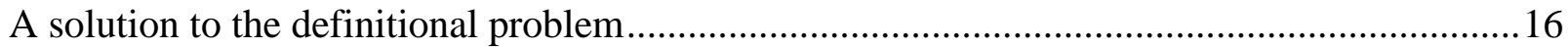

Studying charisma: Challenges and recommendations ....................................................20

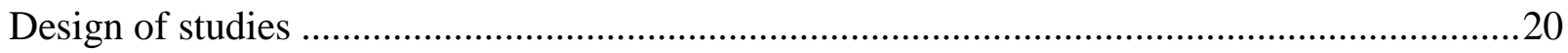

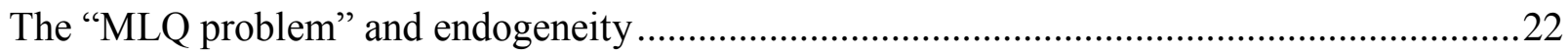

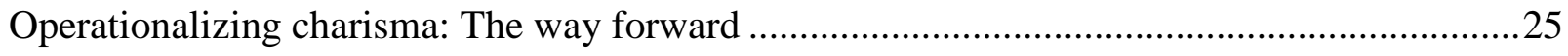

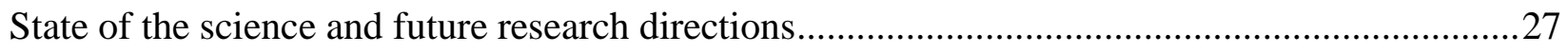

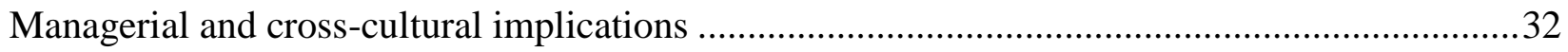

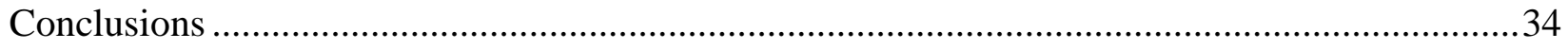

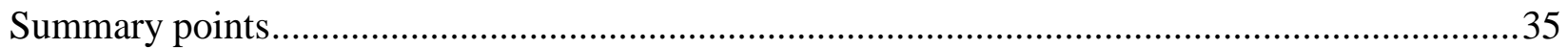

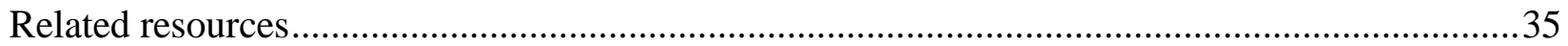

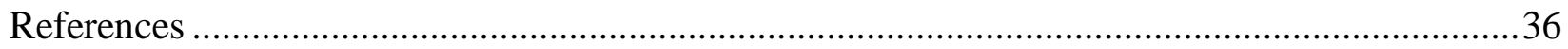

Figure 1: The core of the intellectual landscape of the socio-scientific study of charisma ...........43

Figure 2: Publishing Trends: Number of articles using the term "charisma" or variants ............45

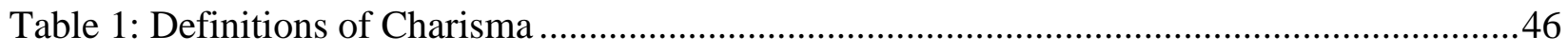

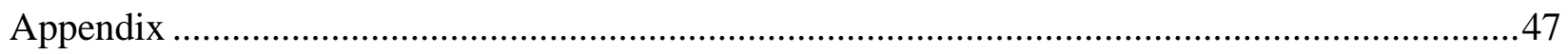




\section{Introduction}

What is charisma? Most scholars and lay people have some sort of implicit notion of what charisma is, the "you-know-it-when-you-see it" phenomenon. As it refers to leadership, many use the term to refer to some sort of gift, charm, or alchemic ability—inaccessible to most— that some leaders have making them able to federate followers around a cause. Yet, thinking of charisma in such terms makes for a fuzzy concept to study. How can we measure such a gift? Is it really a "gift," does it depend on individual differences like personality or intelligence, is it a context-triggered phenomenon, or a set of skills that can be developed? What is the nature of this concept and does it have consequential outcomes?

Despite decades of research on the topic, answers to these questions are not so clear, and this for a myriad of reasons that we will discuss in this article. Some have even gone on to suggest that charisma is "illusionary . . .U.F.O. phenomenon," a "black hole," and a "social delusion" (Gemmill \& Oakley 1992, p. 119). Of course, there is a lot of good research that has been done on charisma in various fields, which we will cover and critically discuss in our review. However, how the concept is defined and has evolved, the theories of charisma that dominate the literature, and the ways many researchers have studied and tested the concept have not helped research advance by much.

Charisma has been the subject of much research since House (1977) introduced it to organizational scholars and psychologists. However, the concept is typically ill-defined by using exemplars or by defining it by its outcomes (Antonakis et al 2011, van Knippenberg \& Sitkin 2013), which cannot help research advance (MacKenzie 2003). Moreover, measures of charisma, using typical behavioral questionnaires, might not be capturing the construct appropriately and such measures of charisma might be outcomes of other factors themselves (Antonakis et al 2011, 
Yukl 1999). Making matters even muddier is that entire research programs, which have dominated the field for decades (Gardner et al 2010, Lowe \& Gardner 2000), have been developed around questionnaires, where the measures per se are used to define the theory. This state of affairs is unfortunate because the theory has not been prospectively described and operationalized (van Knippenberg \& Sitkin 2013).

Adding to the confusion is that the concept of "charisma" is frequently equated to or confounded with another hazy topic in organizational behavior, "transformational leadership" (Yukl 1999). And, despite the best efforts of scholars to constructively critique these two constructs so that leadership research can move on (e.g., van Knippenberg \& Sitkin 2013), equating two fundamentally different concepts like charisma and transformational leadership has made the fog over the leadership landscape thicker still.

The goal of our review is to bring some clarity to the field by untethering charisma from transformational leadership theory and measurement, pointing out the conceptual gaps, definitional problems, and methodological shortcomings, and providing fresh ideas to researchers so that a new genre of studies can help advance a concept that has immense importance for society. Doing so is vital for theory development and the empirical research that it will trigger. However, it is important for practice too because charismatic leaders wield enormous power and can use this power to accomplish great good or evil; thus it is essential to understand what charisma is, its antecedents, moderators, and consequences (Antonakis 2012). We think it is time to take the construct of charisma to the next level.

In this review, we will take historical stock of charisma, tracing its origins and how it has been conceptualized in the sociological (e.g., Shils 1965, Weber 1947) and organizational psychology literatures (House 1977, Shamir et al 1993). In addition to identifying conceptual denominators in definitions of charisma, we will compare and contrast various ways in which 
charisma has been studied in terms of research approaches or designs (e.g., quantitative, qualitative, theory), and how it has been measured, including content coding (Emrich et al 2001, House et al 1991, Simonton 1988) and questionnaires measures (e.g., Bass \& Avolio 1995). We will also examine how it has been manipulated (e.g., Howell \& Frost 1989), whether it can be developed (Frese et al 2003), as well as its outcomes (Fanelli et al 2009). We will also highlight how it should be studied in a causal manner (Antonakis et al 2010) and discuss implications for practice and policy.

Note, typical of reviews of this nature, our positions, coverage, and critiques rely on our professional judgments and how we have interpreted the development of the field over time; however, given the nebulosity and heterogeneity of the charisma construct, and the fact that it has been studied across various fields, to ensure that we were comparatively objective in our coverage and positions we report too on some data regarding a systematic review of the literature that we also undertook (for details, follow the Supplemental Material link in the online version of this article or at http://www.annualreviews.org/). We also use co-citation analysis (c.f. White \& Griffith 1981), and in particular document co-citation analysis, to chronicle the core works in the field (Tsai \& Wu 2010). This analysis will provide us with a picture of the intellectual landscape on which articles writing on charisma have built, and help us better understand whether these studies have drawn from a single unified body of knowledge or from multiple unconnected bodies of knowledge.

\section{A brief history of research on charisma}

The term "charisma" is usually credited to the writings of the Max Weber. He borrowed, secularized, and expanded the term from literature on religion (Sohm 1892), and referred to charisma as an extraordinary power, giving leaders salvationist qualities to deliver followers from 
great upheaval (Weber 1947, Weber 1968). Variants of the term "charisma," however, predate Sohm as well as biblical sources, and have roots in classical Greek mythology - the graces, Charites, and in particular the goddess Charis (Smith 1998). The term charis signifies much in classical Greek; in addition to gratitude (as in eucharist), it can refer to charm, excitement, beauty, pleasure as well as allurement (Maclachlan 1996).

Charis is a complex word that has been the basis of other words. Of course, we are concerned with charisma in leaders and their influence over others and not of charisma as applied in lay terms to individuals in general. It is not difficult to see why this word was chosen to undergird and describe a type of leadership that can give leaders great power, that is, "the discretion and the means to asymmetrically enforce one's will" over entities like organizations or individuals (Sturm \& Antonakis 2015, p. 139). Also, although the term charisma was not originally used by the ancient Greeks to describe a type of leadership per se, Aristotle (1954) did describe how leaders should persuade followers by demonstrating character and defending values, stoking follower emotions, and using strongly reasoned argumentation (the ethos, logos, and pathos); in fact, Aristotle's insights on the rhetoric of leadership, as well as the importance of persuasive devices like metaphor has provided a basis on which modern ideas of charisma have evolved (Den Hartog \& Verburg 1997, Shamir et al 1994, Willner 1984).

\section{The foundations: Sociology and political science}

Weber's ideas about charisma have been enormously influential, and were popularized by sociologists, political scientists, psychologists, and management scholars (e.g., Bass 1985, Davies 1954, Downton 1973, Etzioni 1961, House 1977, Shils 1965). Weber, however, was not very precise about the nature of charisma (Riesebrodt 1999, Shamir 1999). For instance, Weber (1968) suggested that charismatic leaders held "specific gifts of the body and spirit [that are] not 
accessible to everybody" (p. 19) and that charismatic authority resulted from "times of psychic, physical, economic, ethical, religious, [and] political distress" (p. 18); for Weber, crisis and social distress were thus important conditions from which charisma emerged. Weber (1947) suggested that such leaders were mages having been "endowed with supernatural, superhuman, or at least specifically exceptional powers or qualities" (p. 358). As a result, Weber (1968) argued that charismatic leaders create devoted followers who help their leader on a mission that arises out of "enthusiasm, or of despair and hope" (p. 49).

Important for Weber was the notion that the very goals of a charismatic leader are different to those of institutional methods of influence. Weber viewed charisma as radical force wherein "charismatic domination is the very opposite of bureaucratic domination," working against methodical, rational, and economic ideals (Weber 1968, p. 20). Charisma's impact is felt on an emotional level, is "revolutionary and transvalues everything; it makes a sovereign break with all traditional or rational norms" (Weber 1968, p. 24); yet, with time, charisma's effects wane and bureaucracy takes over. The charisma-bureaucracy seesaw continues as relevant contextual factors become propitious for one or the other.

Of course, Weber's ideas and insights have been useful in terms of putting charisma on the leadership nomological map (and indeed $74 \%$ of the articles we reviewed make reference to Weber's work; also, see Figures 1A and 1B). Yet, using Weber's ideas makes it difficult to understand the nature of charisma and to study it systematically, and raises several important questions: What is the nature of the gift and how can it be measured? What kinds of supernatural or superhuman qualities do these leaders have? Is charisma always born in the crucible of crisis? We will address these questions as we review research on charisma, how it is defined, and the nature of the charismatic effect.

[Figure 1A and 1B here] 
Sociologists popularized Weber's ideas, and were instrumental in laying the groundwork from which psychological theories (e.g., House 1977) of charisma evolved. Sociologists were grateful to Weber, and attempted to move the concept from one that was overly focused on psychological attributes and "gifts" of charismatic leaders to one that looked at charisma in a broader social context (Friedland 1964). Essentially, much of sociologist's thinking concerned charisma's institutional (and structural) character, how individuals straddle organizational and personal sources of influence, and how these forces can be reconciled to benefit both the organization and the individual (Shils 1965).

Key to some of this thinking has to do with need to maintain an ordered and stable social system in which individuals can develop, progress and find identity, and the role of charisma in this process (Shils 1965). Sociologists were thus keen to look at the secular nature of charisma, one in which the leader is seen as a "master of events," one that is able to resolve "existential chaos," who "structures a cosmos," and "provides guides for action and a promise for the future" (Spencer 1973, p. 345). For Spencer charisma consisted of (a) skilled performance, engendering awe, and (b) having representation (i.e., symbolic based on values), which creates enthusiasm; these two components can depend on the personal characteristics of the leader but also on the situation, and luck too. Thus, charisma is what Spencer termed the "historical product" (p. 352) between the person and the situation; this position is reminiscent of ideas stemming from interactional psychology (Endler \& Magnusson 1976).

Although several other sociologists made important contributions, we focus on the sociological point of view of Etzioni (1961, 1964), whose work on structuralism — based on Max Weber and Karl Marx's thinking_-has important implications for organizational scholars. Etzioni (1964) sought to describe how organizations exhibit both formal-rational and informal-human needs that are at conflict with each other and which must be balanced so that the organization can 
adapt. Key to Etzioni (1964) was how organizations handle differences in power and the goals that are pursued in hierarchies (i.e., between management and workers). Thus, the leadership style adopted by management was an important determinant of an organization's success because "Most organizations most of the time cannot rely on most of their participants to internalize their obligations, to carry out their assignments voluntarily, without additional incentives" (Etzioni, 1964, p. 59). Given this principal-agent problem Etzioni (1964) differentiated three types of power that leaders could use: (a) physical power entailing the use of threats or coercion, (b) material power entailing the use of rewards, and (c) symbolic (i.e., charismatic) power, a type of normative power that depends on the person (see also Etzioni, 1961). For Etzioni (1964) greater commitment and less alienation will be displayed in workers when leaders exercise symbolic power.

Political scientists also made important contributions to the concept of charisma. Davies (1954) appears to be the first to use the term in this discipline. For him charisma was not "a characteristic of leaders as such but a relationship between leader and followers" (p. 1083). As in sociology, political scientists were eager to try and pin down what seemed to be a "vague" (Friedrich 1961, p. 3) and "nebulous" construct (Tucker 1968, p. 732). For Tucker, charismatic leaders were salvationist or messianic and arose from situational distress; thus, this type of leadership is a process of social influence and not necessarily a position of authority. Tucker was one of the first to identify concrete characteristics of charismatic leaders and suggested that such leaders had good communication skills, were visionary, had a sense of mission, believed in the righteousness of their values and ideals, and had confidence that the vision can be achieved.

Other important contributors to the charisma concept include Downton (1973), who wrote a theory of inspirational and charismatic (as well as transactional) leadership in revolutionary settings. Burns (1978) proposed a similar theory of transforming (and transactional) leadership 
but did not directly refer to the work of Downton (i.e., interestingly, Burns footnoted Downton's work twice and this in a rather oblique way). Burns used the term "transforming leadership," which he described as “elevating, mobilizing, inspiring, exalting, uplifting, preaching, exhorting, evangelizing" (p. 20) to refer to a type of leadership that seemed very reminiscent to what Weber and Downton had called "charisma." In his magnum opus, Leadership, Burns (1978) tiptoed around the concept of charisma, which he thought was beyond analysis, and preferred instead to use the term "heroic" and "ideological" leadership. Burns placed these terms under the umbrella "transforming" leadership; this move was a rather unfortunate one because it appears to be the source that muddied the conceptual waters, as we discuss in reviewing the work of Bass (1985) below.

\section{The edifice: Applied psychology and management}

In the 1970 the state of leadership research was under severe threat (Greene 1977) with calls even to abandon studying it (Miner 1975). It was House (1977) who set the stage to heave leadership research out of the doldrums. Coincidently, charismatic leadership as a topic had a messianic effect on leadership research at time when leadership as a scientific construct was not taken seriously by many scholars working in applied psychology, organizational behavior, or management (Antonakis 2012, see also Hunt 1999). It is encouraging to see how interest in charisma has grown over time (see Figure 2).

[Figure 2 here]

Of course, scholars have a keen interest in understanding leadership, particularly its psychological foundations, which has immense practical importance, particularly for organizations. In doing so, however, such scholars were accused of having jettisoned the original Weberian ideas - relating to crisis, revolution, and charisma as a very unusual characteristic of a 
person - which were held so sacrosanct by sociologists, to study a more tame and ordinary form of it (Beyer 1999). Such qualms were made early by sociologists too about the vulgarization of the term "charisma" (Bensman \& Givant 1975). However, studying a more "ordinary" version of it provides important advantages because "organizational charisma" can be found and studied in various settings (Shamir 1999), which are not necessarily crisis prone; indeed, crisis is not necessary for charisma to emerge, as several commentators have suggested (Conger \& Kanungo 1998, Etzioni 1961, House 1999, Jacquart \& Antonakis 2015, Shamir \& Howell 1999).

House (1977) presented the first psychological theory of charismatic leadership suggesting that such leaders create intensive emotional interactions with their followers. He suggested too that such leaders are usually, but perhaps not necessarily, born of crisis and are seen as saviors as well as role models and objects of identification. House (1977) argued too that these leaders challenge the status quo and "through their leadership major social changes are accomplished" (p. 189). House (1977) presented an amalgam of characteristics and behaviors of charismatic leaders, noting that charisma is essentially based on ideological goals; he noted too that such leaders paid attention to image management, set high expectations, communicated confidence in goal attainment, and role-modeled desired behaviors. House also carefully discussed the psychological outcomes and states that charismatic leaders would have on followers. For House, charisma was not really a "gift" or some magical ability, but rather a complex interaction between the leader, the prevailing context, and follower needs. He articulated several testable propositions about his theory and challenged researchers to measure charisma and identify how it impacts followers.

The gauntlet that House (1977) threw down was taken up by Bass (1985); basing his work on Burns (1978) and House (1977), Bass articulated a theory that bore some strong overlap to that of Downton (1973) — but to whose work he did not refer. Bass's (1985) ideas have had an 
enormous impact on leadership search, as evidenced in Figures 1A and 1B (see also: Antonakis et al 2014a, Gardner et al 2010, Lowe \& Gardner 2000). We thus will focus on his theory extensively, also because it is the reason why there is so much confusion about charisma and transformational leadership; at the same time, we do also wish to credit other important contributions that were made by other researchers to the study of charisma (Berlew 1974, e.g., Bryman 1992, Conger \& Kanungo 1987, Conger \& Kanungo 1988, Conger \& Kanungo 1998, Conger et al 2000, Gardner \& Avolio 1998, House \& Howell 1992, Howell 1988, Howell \& Frost 1989, Shamir 1995, Shamir et al 1993, Waldman \& Yammarino 1999); some of these are highlighted in Figure 1A.

Bass reworked the entire notion of charisma with a focus on measuring it, and placed it under a class of leader behavior he called "transformational leadership." Similar to the title of his book, Leadership and Performance Beyond Expectations, he defined transformational leadership as a type of leadership that "motivates us to do more than we originally expected to do" (p. 20) and "used to describe leaders who by the power of their person have profound and extraordinary effects on their followers" (p. 35). Apart from using a very loaded term "transformational" (Antonakis 2012), his definition is not helpful because transformational leadership is defined by its outcomes (see section on "Defining Charisma" for further elaboration on this problem). Thus, what is transformational leadership? Most would say that it is about leaders who are able to transform; however, this is not a definition but a tautological statement.

Bass's core idea was to articulate a theory of leadership going beyond the simple provision of rewards or punishments contingent on performance, which he termed "transactional leadership," by proposing a style of leadership that explained extraordinary performance and commitment in followers, which he termed "transformational leadership." He identified this new type of leadership by asking executives to describe exemplars. On the basis of this pilot study and 
a review of the literature, he identified and also developed items that represented influence and charisma (as well as transactional leadership). Then using judges, he identified what were seen as the most prototypical items for the major classes of leader transformational and transactional behavior and tested these items in various samples using factor analyses. Bass (1985) stated explicitly that the results from these analyses "were the basis for structuring this book" (p. 207) and hence the theory. Although he reviewed literature on the topic, primarily the works we cited above (i.e., those of Weber, Burns, House, and others), the way in which he conceptualized charisma was inductive, leading to conceptual ambiguities (van Knippenberg \& Sitkin 2013, Yukl 1999). Not providing a conceptual definition and using measures to develop a theory have created a very unsatisfactory situation that has impeded advancement of this construct (van Knippenberg \& Sitkin 2013); still today, the nature of transformational leadership is not clear.

The theory is basically defined by its measurement instrument, the Multifactor Leadership Questionnaire — the MLQ—which has undergone numerous revisions (Bass \& Avolio 1995); it is used to measure leadership via self or observer reports. For Bass (1985), the core of transformational leadership was charisma (see also Bass 1990, p. 199)—charisma provided the emotional component of leadership. He also suggested that charisma and transformational leadership were asymmetrically related in that not all charismatic leaders were transformational. In the current version of the theory (i.e., the MLQ), charisma is called "idealized influence" having a (a) behavioral as well as an (b) attributional component to it; theoretically charisma is also tapped by a factor named (c) inspirational motivation. These three dimensions, along with the (d) rational component of transformational leadership called intellectual stimulation as well as (e) a developmental oriented factor called individualized consideration, comprise what is known as "transformational leadership" (Antonakis et al 2003). 
Apart from issues concerning conceptual definitions, there are several problems with this theory and questionnaire. By far the biggest problem has to do with equating transformational and charismatic leadership: Although Bass argued that charisma is part of transformational leadership most researchers confuse the two constructs or suggest they are one and the same. These two concepts are distinct and one should not been seen as a subcomponent of the otherthat is, a leader could be transformational without being charismatic, or vice-versa (Yukl 1999). Furthermore, the two constructs may even be even incompatible. Being charismatic may constrain the extent to which the leader could be "transformational" (i.e., empowering and developmental); additionally, being too developmental, attentive, and empowering may limit the extent to which the leader can be attributed charisma because the leader will not be seen as extraordinary enough (cf. Yukl 1999). Thus, it is unfortunate too that even well-meaning critics (i.e., van Knippenberg \& Sitkin 2013) have suggested that these two constructs are isomorphic and this, on the basis of high correlations between scales of the constructs. That factors or items from the two constructs - using what we think is an inappropriate questionnaire to measure charisma as an independent variable - correlate highly is not proof that they are measuring the same thing. This correlation can be explained by endogeneity bias (i.e., confounding variables) as well as other sources of bias. We elaborate on this problem later (see the section titled The " $M L Q$ problem" and endogeneity).

In conclusion, and as will become clearer in the following sections too, charisma (a) is construct that should be studied and modelled in its own right and must be unleashed from transformational leadership, (b) requires a clear definition, (c) must be operationalized following the definition, (d) cannot be measured as an independent variable using current behavioral questionnaires and usual statistical methods (because of endogeneity), and (e) must be measured 
in an objective way not prone to cognitive or endogeneity biases (see Appendix for a brief introduction to the endogeneity problem).

\section{Defining Charisma}

Before we provide what we believe to be useful definition of charisma, we first discuss how charisma should not be defined. We discuss this issue extensively because most research programs on charisma, beginning with definitions, require a keelhauling. Key to understanding charisma is first defining it correctly; however, there are many problems and issues with current definitions of charisma, which have impeded our scientific progress.

\section{Problems with current definitions}

We begin with the simplest of the problems in prevailing definitions with two analogies: Imagine if scholars (a) defined effective companies as having divine qualities or (b) measured effective practices in companies to predict company effectiveness. The problems of undertaking research in this manner are immediately evident. Scientific fields can only progress if the phenomenon studied is defined precisely and that the nature of the underlying phenomenon is unveiled without making for a tautological definition and estimation.

To better understand the problem, we begin by showcasing a typical definition of charisma, which goes like this: "Charisma has been defined as a characteristic of individuals who 'by force of their personal abilities are capable of having profound and extraordinary effects on followers"” (Wowak et al 2014, citing House, 1977). What is the problem with such a definition? Constructs should not be defined in terms of their outcomes, their antecedents, or using exemplars (MacKenzie 2003). Useful definitions would require the construct, charisma, to be independent of its effects and specify the nature of the phenomenon in a prospective way. Of course, empirical validation of the effects of the construct on outcomes (e.g., worker 
productivity) is required to demonstrate the construct's utility; however, the construct cannot be defined in terms of the outcomes it should produce. Yet, as has been recently noted (Antonakis et al 2011, van Knippenberg \& Sitkin 2013) charismatic leadership has usually been defined precisely in this way. Worse, it is defined in undefined terms. For example, Davies (1954) suggested that charisma is "miraculously-given power" (p. 1083). Such a definition is not clear as to the nature of this power. Etzioni (1961, p. 203) stated charisma is a relational property and "the ability of an actor to exercise diffuse and intense influence over the normative orientations of other actors"; such a definition uses outcomes and it is not clear how or why these outcomes are produced. We find the same problem with the definition of Spencer (1973, p. 352) for whom the essence of charisma is evident "in an attitude of awe and enthusiasm."

Yukl (1999) suggested that "The most useful definition seems to be in terms of attributions of charisma to a leader by followers who identify strongly with the leader" (p. 294); again, using outcomes in a definition cannot clarify the nature of the concept. Bass (1990, p. 220) avoids defining charisma altogether, though the closest he gets to a definition is with the following: "a person of strong convictions, determined, self-confident, and emotionally expressive and his or her followers must want to identify with the leader as a person, whether or not in a crisis." Yet, this definition will not help science progress, as we explain below with respect to the problem of defining charisma with antecedent traits (beyond the other problem of including outcomes in the definition). Even House (1977) defined charisma by its outcomes. After having articulated the effects that charismatic leaders have on followers, he noted that the "term charismatic leadership will be used to refer to any leader who has the above "charismatic effects" (p. 192). However, in his defense he was suggesting that studying leaders who create these effects may help to identify their characteristics, which would help to distinguish them from leaders who do not produce charismatic effects. 
To determine where the state of the field is with respect to defining charisma, we coded the definitions of charisma provided explicitly in our reviewed articles, to find the lowest level conceptual commonalities of elements in definitions, showing which are useful or not for a definition of charisma (see Table 1). It is unfortunate to note that most scholars have defined charisma as some kind of unknown quality, ability, or gift of a leader. Many define charisma by its outcomes, and most other elements in the definitions we found are simply not useful to explicate the nature of the construct and to distinguish it from others. Defining charisma as an attribution is also problematic because an attribution is an outcome - or has to be modelled as mediatory process to predict another outcome - which depends on some sort of leader action.

Defining charisma as a social (relationship) process or leader behaviors and actions is not very useful because all types of leadership are predicated on processes, behaviors, and actions. Also, stating that charisma depends on follower characteristics again renders it is an endogenous construct, and endogenous variables can only be used as outcomes or "instrumented" mediators, and not as regressors; as such it would not vary randomly in individuals and be beyond manipulation (and thus be very hard to study). Moreover, charisma does not require a crisis to emerge (which in any case violates a good definition by specifying an antecedent). And, social cognition, whether attribution or inference based is a foundation for the evaluation of all types of social relationships (see Jacquart \& Antonakis 2015). Furthermore, using antecedent traits or traits per se to define charisma does not help elucidate the nature of the charisma construct because such traits can be predictive of other forms of leadership too.

[Table 1 here] 


\section{A solution to the definitional problem}

The elements of a definition of charisma that we consider to be useful include defining it as a type of leadership whose nature is based on values (i.e., morals), beliefs and symbolism as well as on emotion, which is expressive in its transmission of information. We omit using the word "vision" in the definition, because vision is really quite a vague notion, which in any case stems from using symbolic means of communication that are useful for triggering a mental image and hence a vision (Antonakis et al 2011). Although we could use the term "ideology" in a definition of charisma, we will omit it so as to not confuse charisma with "ideological leadership," a type of leadership that is predicated on defending some tradition (Mumford et al 2008). Of course, ideology is based on values; thus, ideologues can also be charismatic but not all charismatic leaders are necessarily ideologues.

Also, to help better identify the nature of the charismatic effect, we draw from economics, which has not made many contributions to leadership yet, but which has some sound thinking with respect to the incomplete and asymmetrical nature of information between players in markets (Spence 2002). The market we refer to is leader selection or emergence, which includes (a) leaders (b) followers of leaders, who accord leaders status (informally) by virtue of following them, and (c) leader selectors acting on behalf of principals, who formally appoint leaders to positions of authority. In this market, leaders engage in signaling; signals can be thought of as "things one does that are visible and that are in part designed to communicate" (Spence 2002, p. 434). Via signaling, leaders can win selection tournaments or be accorded status by followers, whether they are formal or informal leaders. As regards followers, leaders need to signal them some information about what kinds of actions they should engage in via leader role-modeling (cf. Hermalin 1998) and from value systems leaders communicate. Also, leaders need to signal about 
their own skills (Spence 2002). Thus, what choices leaders take or what actions they value can, via signaling, help solve coordination problems in public goods situations by affecting follower choices and actions as well as beliefs about what others may do.

Also, with respect to followers per se, given that the nature of leadership as an influencing process is not one of authority but one of voluntary following (Hermalin 1998), we think that the term "signaling" as a general mechanism of information communication should also appear in a definition of charismatic leadership. Note that signaling can occur via verbal and nonverbal communication modes (Awamleh \& Gardner 1999, Frese et al 2003, Towler 2003, Willner 1984); and, interestingly, those who are high on use of verbal communication means are high on nonverbal too (Antonakis et al 2011) presumably because rich verbal communication means (e.g., storytelling) require more nonverbal gesturing (Jacquart \& Antonakis 2015, Towler 2003).

Important here too is to avoid using the term "influence" in a definition of charisma. Influence connotes having an ability to impose oneself; however, what is the nature of this ability and why does it occur? Moreover, influence in terms of being "influential" is an outcome. Hence, "signaling" and "influence" are separate constructs and because of signaling the leader is able to influence (the dependent variable) under certain conditions. Therefore, following the above, as well as previous definitions of charisma (cf., Antonakis et al 2011, Tucker 1968) we provide the following general definition: Charisma is a values-based, symbolic, and emotion-laden leader signaling.

A charismatic leader is one who signals using the aforementioned mechanisms noted in the definition. Following this definition, an individual can be charismatic without having any influence whatsoever. For the charismatic effect to occur, and for the followers to willingly succumb to the leader's influence, the leader must be accepted by followers because he or she is communicates values and a mission that appeals to the followers. Theoretically, the "connection" 
(i.e., the charismatic effect) that a charismatic leader has with his or her followers, and why the followers identify with the leader, stems from the leader (a) justifying the mission by appealing to values that distinguish right from wrong, (b) communicating in symbolic ways to make the message clear and vivid, and also symbolizing and embodying the moral unity of the collective per se, and (c) demonstrating conviction and passion for the mission via emotional displays (Antonakis et al 2011). To the extent that such signalling on the part of the leader resonates with the values of the collective, the leader will appear prototypical to followers (Hogg 2001); indeed, charismatic leaders can be loved but also much loathed by those who do not share in the leader's values (Tucker 1968). It follows too that the more prototypical the leader seems, the more followers will attribute certain qualities to the leader like courage, wisdom, competence, and so forth (for more precision, we should use the term "infer" instead of "attribute"; the former concerns describing what one is like and the latter the cause of an outcome, see: Erickson \& Krull 1999, Jacquart \& Antonakis 2015).

Note, as far as we are concerned, and for the purpose of the above definition we are not assuming that the leader's signals necessarily carry accurate information about the competence or moral righteousness of the leader's ideals; however, observers will use these signals to attribute certain qualities to the leader and to give him or her the benefit of the doubt in situations of strategic uncertainty, whether this uncertainty comes from uncertainty about the previous performance of the leader or environmental uncertainty (Jacquart \& Antonakis 2015). These elaborations should be considered in theories along with questions like: under what conditions does charisma as a signal convey credible information to followers as well as other interested parties (e.g., investors) about the skills of leader? That is, does charisma correlate with unobserved leader abilities? Tellingly, Aristotle mentioned the following about the use of symbolic communication (and the use of metaphor in particular, which is a core component of 
symbolic communication, Antonakis et al 2011): "But the greatest thing by far is to have a command of metaphor. . . it is the mark of genius" (Aristotle \& Butcher 2011). Also, can we assume that the skills of charismatic leaders can be acquired at a lesser cost by more able leaders; or, do they depend directly on the natural endowments of leaders, that is, their intelligence and personality, which are heritable to a large degree (Bouchard \& Loehlin 2001, Bouchard \& McGue 2003)? And, given the assumed difficulty for a low-ability leader to acquire such skills, does the market for leaders naturally sort itself in a way such that only high-ability leaders signal charisma?

Armed with a definition of charisma, researchers can focus on building a comprehensive exposition of the nature of the charismatic effect including antecedents, mediatory mechanisms, boundary (moderator) conditions, and outcomes, and this at different levels of analysis. Doing so will allow for the development of a complete and general theory of charisma, ideally at the interface of psychology and economics.

Finally, our definition is not concerned with the ultimate morality the leader per se (see Howell 1988). Although we do, as researchers, care that leaders use their power to serve the greater good, scientific definitions should not dabble in normative outcomes, which are more of a philosophical concern. As far as our definition is concerned, that the signaling process is values based suggests that the leader will be judged by the values and morals he or she communicates. Also, the leader must appropriately communicate about actions in which the collective should invest; leaders do so via beliefs and expectations and this using symbolic communication means (e.g., metaphors) and displays of emotions in a correctly-calibrated and appropriate manner. Thus, there are costs and benefits involved in signaling, not only in terms of having the ability to produce the signal, which we assume will mostly be available to high-ability leaders, but also with respect to what outcomes the signals can engender per se for the leader and the collective. 
Leaders cannot say one thing and do another, or signal unrealizable actions because in the long run they risk losing their credibility and hence the charismatic effect. Thus, leaders must appropriately pitch their signal as a function of their ability. Hence, leaders who are charismatic and whose values are accepted should in the long run have better performance outcomes than will leaders who are charismatic and whose values are not accepted or, leaders who do are not charismatic.

\section{Studying charisma: Challenges and recommendations}

Given the challenges we have identified with respect to how charisma is being defined, it will not come as a surprise that studying this concept will prove to be difficult. In this section, we briefly review and critique how charisma has been studied with respect to design, operationalization, and the endogeneity problem.

\section{Design of studies}

Developing theory to explain phenomena including understanding causal relations between variables as well as the conditions under which relations between the variables hold is an important part of research (Bacharach 1989). Because of the enormous complexity of the charisma construct and the diversity of researchers studying it, there has been a variety of ways to go about studying charisma. What is the best way to study charisma? Are some ways more impactful than others are? These questions are particularly interesting given the differences in history and traditions in the two major disciplines that study charisma, sociology and psychology. Researchers in the former are more open to qualitative (and "post-positivist" approaches) whereas the latter are more quantitative and experimental.

Currently, the dominant way to study leadership is the quantitative design, as ascertained recently in lifetime bibliometric study of articles published in the top field journal specializing in 
leadership research, The Leadership Quarterly (Antonakis et al 2014a). Yet, the qualitative mode of inquiry has been suggested as a potent complement but also an alternative to quantitative methods; given the complex and contextually sensitive nature of the leadership phenomenon, the qualitative method has been proposed as especially relevant and useful for studying charisma (Conger 1998). However, in comparison to qualitative articles, quantitative — as do theory, review and methodological—articles have a more significant impact on the field, as measured by the citations received; furthermore, qualitative articles are typically under-represented in top-cited papers (Antonakis et al 2014a).

As with previous research, we found that qualitative papers are undercited in comparison to other types of articles (see online Supplemental Materials). Does the "citation market," which represents the collective wisdom of field as a whole have it right insofar as studying charisma is concerned? We cannot answer this question. However, we believe that to advance a field we need theories. Review articles, such as the current one, are helpful for taking stock and guiding future research efforts. Then we need to test theories, which can only be done reliably in a quantitative manner. Quantitative designs, if correctly done, offer many advantages for testing counterfactuals and causal relations, and hence informing policy. This method of inquiry can still be used with qualitative data because qualitative information can be coded in a straightforward way (in many if not most cases).

With the increased availability of modern computing power and advanced statistical methodology, contextual and multilevel information can now be readily coded and included in statistical models. Given the current state of research for quantitative modeling across a whole range of effects and conditions, and the capabilities of modern software, we think that researchers should move more towards theory testing using experimental designs (Brown \& Lord 1999). As the old adage generally attributed to Kurt Lewin goes: "The best way to understand something is 
to try to change it." Also, appropriately-done field studies and "natural experiments" that can avoid endogeneity threats are also very useful and probably more relevant too (Antonakis et al 2010). Going more towards the quantitative way will nonetheless require a radical overhaul of how researchers go about measuring charisma, as we discuss next.

\section{The "MLQ problem" and endogeneity}

As mentioned recently by Day (2012, p. 862) "questionnaires remain a popular (if misguided) approach to studying leadership. If you design and publish a brief, easy-to-administer survey questionnaire, there is little doubt that researchers will use it. But, we should not lose sight of the fact that a map is not the territory, and simply labeling a questionnaire as a measure of 'leadership [or charisma] measure' does not mean that it actually measures leadership [or charisma]."

Are questionnaire measures really a problem? We think mostly yes and there are very specific reasons why we take this position. Questionnaire measures of leadership, using ratings of observers (typically subordinates, but also peers or supervisors) started becoming popular in the 1950s and 1960s (Fiedler 1967, Fleishman 1953, Katz et al 1951, Stogdill 1963). Currently, there seems to be "create-a-questionnaire" bandwagon sweeping through our field to measure all sorts of constructs; many of these are poorly defined and operationalized (Day \& Antonakis 2013). Researchers use questionnaire measures probably out of convenience or simply because they have been trained to or because everyone else does it. It certainly is a "quick and dirty" way to obtain data. Yet, such measures do not get to what charisma is - in terms of an independent variable - no matter how big the statistical hammers are, which are used to "confirm" the factor structure of the measures. 
By and large the "new" leadership (Bryman 1992), which includes charismatic leadership, dominates the leadership landscape (Antonakis et al 2014a) with the MLQ being the most-used measurement instrument both of the "new" leadership (Antonakis \& House 2014) as well as of charisma, as the results of our review show (see online Supplemental Materials). The use of the MLQ is growing, which is an unfortunate trend to observe because this instrument does not measure charisma as an independent variable but mostly outcomes of charisma or charisma as an endogenous variable (Antonakis 2012, Antonakis \& House 2014, Shamir et al 1998). Constructs that are endogenous cannot be used as regressors in a model to predict other outcomes unless corrective action is taken to remove the endogeneity bias in the leadership construct (see Appendix I. Also see Antonakis et al 2010, Antonakis et al 2014b, Bascle 2008, Duncan et al 2004, Larcker \& Rusticus 2010).

To highlight the nature of the problem, we provide a brief example using an item from the Idealized Influence Attributes scale of the MLQ (e.g., "Displays a sense of power and confidence"). A leader could do more or less of the behavior or any other leader behavior for that matter (Antonakis \& House 2014, Bryman 1992, Hunt 1991), depending on various factors at the leader level (e.g., how extraverted the leader is) or at the organizational level (e.g., selection, training, or resources provision). These factors will correlate with outcomes of leadership too; thus, omitting these factors from a predictive model cause endogeneity bias. Moreover, the leader's behavior may even depend on how performing a subordinate, workgroup, or organization is (i.e., leaders become more confident with better performance, which does not stem from the leader; or leaders may adjust their behavior and "crack the whip" more if followers do not perform well). This bias is called simultaneity bias, a form of endogeneity that confounds estimates. Indeed, many of the items of the MLQ measuring transformational leadership scale are endogenous, as are items from most other leadership scales. 
Apart from pure omitted variable bias, there are also biases affecting raters, stemming from cognitive classification mechanisms. For instance, if a leader is effective due to other factors that are not captured by the MLQ (e.g., instrumental/expert leadership, or charismatic leadership in the true sense of the word), the leader will be classified as being effective, which will trigger a cognitive "fill-in-the-blanks" mechanism (Cantor \& Mischel 1977, Lord et al 1984); in this way, any prototypically good factor of leadership will covary positively with the outcome due to its correlation with the omitted cause (Antonakis \& House 2014). There are also other biases like affect for the leader, which may stem from many reasons other than those measured. (see also Mount \& Scullen 2001, Scullen et al 2000).

Finally, raters can also be biased directly because of "performance-cue" effects. That is, raters who have knowledge of leader outcomes will be biased when rating behaviors that theoretically can cause the outcomes (Jacquart \& Antonakis 2015, Lord et al 1978, Meindl \& Ehrlich 1987). Again, via attribution mechanisms, raters are "filling-in-the-blanks" as described above, but in this case the omitted variable is the outcome per se, which is also an endogenous variable.

Questionnaire measures could certainly be used to study charisma; however, they must be modeled as endogenous variables (i.e., outcome variables), predicted by what are known to be exogenous variables such as manipulated variables or stable individual differences. Questionnaire measures could be used as endogenous regressors of other endogenous variables if appropriate statistical techniques are used to purge the scales from endogeneity bias (as discussed in the Appendix); using these techniques can significantly change the validities of such measures (Antonakis \& House 2014). The use of such corrective procedures is unfortunately an exception rather than the rule. Of course, issues of endogeneity bedevil all behavioral questionnaires, in particular those that measure outcomes of leadership per se in an obvious way like quality of 
leader-member exchange or LMX. Thus, much of the literature using questionnaire measures is plagued by endogeneity issues and cannot inform theory or policy. To move forward we provide suggestions about how charisma should be measured and a way that will avoid many of the issues we identified above.

\section{Operationalizing charisma: The way forward}

As suggested in the previous section, using questionnaire measures of charisma is only defensible if charisma is modeled as an endogenous variable. We think that the most promising ways to measure charisma as an independent variable are either to (a) use unobtrusive and objective measures that do not rely on perceptions of raters, like different types of archival data (xxxxxxx in press) or (b) manipulate it directly in a laboratory or field experiment; perhaps one day (c) better designed questionnaires will get to the gist of charisma.

As concerns unobtrusive and objective measures, Tucker (1968) was one of the first to suggest objective measurement by recommending that markers of charisma be extracted from various sources including biographical (i.e., historiometric) material, and this prior to a leader achieving office so that charisma's effects would not confounded with the outcomes of having power. Given our definition of charisma (i.e., a values-based, symbolic, and emotion-laden leader signaling), markers of leader signaling, both verbal and non-verbal, should be accessible in a variety of artefacts, thus allowing for quantification and testing (Simonton 2003).

These artifacts could be speeches, video materials from interviews or other archival sources or any other form of communication that are ideally detached from outcomes and reflect an enduring pattern of leader signaling (with respect to values as well as symbolic and emotional communication styles). Such an aggregate variable, if relatively stable over time and invariant across situations (e.g., see Jacquart \& Antonakis 2015, in rating speeches of U.S. presidential 
contenders) will unlikely change as a function of what it predicts (i.e., outcomes) or of omitted causes related to these outcomes.

Several researchers have used unobtrusive approaches by coding for markers of charisma. For instance, one way to get a message across in a visual way (i.e., symbolically) is to use metaphors, which can be reliably coded from speeches and which induces charisma (Mio et al 2005). Storytelling is also another technique, which is a bit more complex than metaphors are, but which acts in a similar way (Towler 2003). Coding for value statements can be straightforward (Frese et al 2003). In fact charismatic leaders use a variety of communication techniques (Den Hartog \& Verburg 1997, Shamir et al 1994) to communicate symbolically, and these along with non-verbal delivery techniques (Awamleh \& Gardner 1999, Frese et al 2003, Towler 2003) can be reliably coded from text and video artefacts (refer to the "charismatic leadership tactics" in Antonakis et al 2011, Antonakis et al 2012, Jacquart \& Antonakis 2015). Some simpler verbal techniques may also coded by computer (e.g., Davis \& Gardner 2012).

To better understand charisma too, we think that more experimental studies should be conducted, whether by exposing participants to different treatments (to intervene on the participants' leadership) or to expose them to someone trained to depict a particular leadership style either in person or via video materials (Podsakoff et al 2013). To our knowledge, the first study using a trained actor to manipulate charisma was undertaken by Howell and Frost (1989), who manipulated charisma in terms of nonverbal delivery as well as verbal appeals. An example of exposing participants to a video-taped manipulation includes Awamleh and Gardner (1999). Depending on what is studied, even "paper people" experiments could be useful (e.g., Kosloff et al 2010); however, these cannot fully capture the charismatic effect. Note, though, that most of the experimental studies have been in the laboratory_-such studies come with inherent 
limitations insofar as external validity is concerned with respect to the ecological validity of the task and the sample used.

We are hopeful too that researchers will develop questionnaire measures that better capture charisma as an independent variable. However, getting to the point where charisma will be adequately measured as an independent variable will be very challenging. Perhaps items could better map on markers of charisma that researchers have manipulated (Antonakis et al 2011, Frese et al 2003, Towler 2003), and which, because of their specificity, are not so prone to affect or performance signal bias. For instance, perhaps researchers should consider asking raters to evaluate to what extend the rated leader "uses metaphors when communicating," "tell stories often to convey a point," "often poses rhetorical questions," or "depicts choices in contrasts (i.e., black and white)." Raters, however, might find it hard to accurately recall such details, or such details may even be imperceptible to them. That is, individuals may feel the consequence of metaphor (or storytelling), but not explicitly discern and recall its use or consciously reflect on such linguistic devices (cf. Lakoff \& Johnson 1980). We thus think that extracting features from video or archival material by trained coders or computer would be easier to use. Work sample tests and role plays may also be useful in this regard.

\section{State of the science and future research directions}

Given its immense practical importance, we see a very rosy future for the charisma construct. There is much to be done still in terms of discoveries. Of course, we need to first get our theoretical house in order prior to using correct operationalizations of charisma and appropriate causal tests. Researchers continue to be interested in this construct and at this rate we think that some major advances will be made particularly if studying the construct from multidisciplinary perspectives (e.g., psychology, economics, and biology). 
In this section we briefly discuss where research using charisma should head, based on our judgment, the coded articles, the gaps we have identified, and limitations we see in current approaches. We supplement our suggestion, with brief reports on features we coded from the articles (where relevant) so as to better understand and objectively demonstrate the kinds of variables, contexts, samples and the like being studied by researchers (see Supplemental Material link). We hope that this section will provide researchers with ideas about how to better study charisma.

With respect to the articles we coded for in our review, of the 280 articles we included, most (i.e., 112 articles) were quantitative. Qualitative articles constituted the next largest category (90), followed by theory (69) and review (9) articles. In term of journal targeting, most papers on charisma appeared in field journals with The Leadership Quarterly publishing the most articles (68 articles), followed by Leadership (10 articles), and Journal of Applied Social Psychology (10 articles); in the fourth place came a top general journal, Academy of Management Review (7 articles). The top-five most cited articles, in order, included a theory article by Shamir et al. (1993), followed by another theory article (Conger \& Kanungo 1987), a critique (Yukl 1999), an empirical article (House et al 1991) and finally another theory article (Gardner \& Avolio 1998).

As concerns quantitative papers, from which it was quite straightforward to extract information, most articles studied charisma as a dependent variable, though about a third studied it as an independent variable. Only a few studies modelled charisma as a mediator or moderator; note, we identified 98 other quantitative articles measuring charisma but we excluded them because they failed to model charisma correctly; that is, charisma was measured as an endogenous variable but used as a regressor (note, from these 98 articles, 77 of these modelled charisma as an independent variable and 13 as a mediator). 
With respect to sample locations, half came from the U.S.A.; although most of the work on charisma is being done there, it is encouraging to see that researchers from other countries are interested in studying this concept too. Important to note here is that charisma (or descriptions similar to the term) is universally endorsed as a prototypical characteristic of effective leaders (Brodbeck et al 2000, Den Hartog et al 1999, Koopman et al 1999). Thus, we hope to see much more research on the topic conducted outside of the U.S.A. Doing so will also help in establishing charisma's boundary conditions across different cultures.

In terms of samples used about half of the samples used undergraduate or graduate students as participants (one reason being that we excluded many field studies using working populations due to endogeneity concerns), followed by participants coming from private and public firms; about a fifth were politicians, with the rest coming from other contexts. Moreover, in terms of outcomes predicted by charisma, most were perceptual and only about a quarter were objective. Although perceptual measures are interesting to study, we hope to see more studies using charisma to predict objective outcomes, particularly at the organizational level. We still do not know really if and how charisma influences organizational outcomes (Yukl 1999) as well as other levels-of-analysis effects (Waldman \& Yammarino 1999). Indeed, most conceptualizations and theories have strong individual and dyadic focus (Antonakis \& Atwater 2002) and more research on group as well as on organizational-level outcomes is sorely needed (Beyer 1999, Yukl 1999). Still it is reassuring to see that there is some evidence showing that charisma does matter when using objective outcome measures (e.g., Flynn \& Staw 2004).

Additionally, although we would expect most processes to "work" in the same way across samples (and cultures too), we hope to see more research using realistic contexts and this in design conditions that allow for strong causal inference. Yet again, we are disappointed by the fact that we only found one field experiment done with working populations (Antonakis et al 
2011). Still, it is encouraging to see that about a third of the studies at least used an experimental protocol and about a quarter archival data (the rest being field data). With respect to using experiments and in addition to seeing more field experiments we hope to see too more realistic alternative treatments (i.e., incentivized); simply comparing a charismatic treatment to a placebo treatment does not provide for a strong test. Likewise, tasks that are oftentimes used, particularly in laboratory settings lack ecological validity and are low stakes-we hope to see more consequential tasks having real world analogues (i.e., like work productivity). In terms of manipulations, most studies manipulated the content of the speech or the communication style of the leader, which we find as a good sign. Also about a dozen studies used trained actors - all of which were experimental (as would be expected). We think that this type of design affords very strong experimental control and should be used more often.

There are several other recommendations we have to move the field forward. First, we need to know more about the mediators and moderators of the charismatic effect (van Knippenberg \& Sitkin 2013). At this time, we know more about moderators including leader distance (Shamir 1995), crisis (Bligh et al 2004), leader prototypicality (Van Knippenberg \& Van Knippenberg 2005), leader confidence (De Cremer \& Van Knippenberg 2004), and attributional ambiguity (Jacquart \& Antonakis 2015), among others. However, mediation mechanisms are still in the realm of the theoretical (Shamir et al 1993) and this is so because, unfortunately most researchers have not tested how the effects of charisma are channelled (mediated) appropriately in a causal way (Antonakis et al 2010).

Second, we need more complete theories and more direct tests of the theories. For instance, the highest cited paper we coded (Shamir et al 1993), which happens to be a theory paper, still has not been appropriately tested — using a correct causal specification (see Antonakis et al 2010)—with respect to mediatory mechanisms (i.e., identity states). 
Third, methodological standards need to be drastically improved; publishing research that finds "associations" and "correlations" does not help practice advance. Also, synthesizing endogenous correlations in meta-analyses simply makes for more precise endogenous correlations, which cannot shed more light on cause-effect relations. It is unfortunate to observe that a meta-analysis by DeGroot et al (2000) has reported that the MLQ was used almost exclusively by researchers to measure charisma as a predictor. Another meta-analysis only used the MLQ charisma scale by design (Fuller et al 1996)! There is a sore need for a well-done metaanalysis using correct measures of charisma and this in models that are properly and causally specified.

Fourth, we hope to see more qualitative research, ideally quantified and tested appropriately (Eagly \& Antonakis 2014, Simonton 2003). Purists might argue that such studies are not qualitative anymore; however, even researchers with strong qualitative credentials have suggested that quantification of qualitative data can be very useful (Maxwell 2010); such studies, we think, will be able to shed some unique light onto the charisma phenomenon. Most of the qualitative research we surveyed used case studies; these can be very idiosyncratic that cannot make for very generalized findings. Multiple cases and comparisons are much more useful (Eisenhardt \& Graebner 2007), particularly if quantified (Antonakis et al 2014a).

Fifth, what individual differences predict charisma? Although we have suggested charisma, in its pure form is a marker of leader ability (and as such is trait-like), there should be some stable variables with which it correlates; that is, other measureable individual differences may share some common variance with charisma too. For instance, production of creative metaphors — an important marker of charisma (Antonakis et al 2011) —is predicted by general intelligence (Silvia \& Beaty 2012). Some pointers are provided in Bono and Judge (2004) with respect to personality. However, there are hardly any articles linking one of the most-studied 
individual difference variable, intelligence, to charisma. Also, we do not know enough about how male and female leaders are seen by others, and how effective they are, when using charismatic sources of influence.

Finally, other interesting avenues to explore would be linking perceptual measures of charisma to biological individual differences like facial appearance (Todorov et al 2005, Trichas \& Schyns 2012), height (Hamstra 2014) or other factors (e.g., hormones), as well as to looking at neuroscientific correlates (Waldman et al 2011). As concerns the latter there is some very interesting research showing how charismatic rhetorical strategies like storytelling affects neuroendocrinological functioning (Barraza et al 2015, Barraza \& Zak 2009, Speer et al 2009). Such research would also benefit from using twin studies so as to determine - and this using objective measures of charisma - the extent to which charisma is heritable.

\section{Managerial and cross-cultural implications}

Given the immense attention that practitioners pay to leadership as well as the development of leaders and leadership production systems (Day 2000, Day et al 2014), it is important to consider the practical importance of charisma as well as its generalization across contexts. First, we know that charisma is considered a prototypical characteristic of effective leadership and this across a wide array of cultures (Den Hartog et al 1999). Thus, we think that our recommendations regarding how charisma should be operationalized and studied can be applicable to a wide range of situations and contexts; however, we still need more carefully designed research to determine what bounds charisma's relation with other variables as a function of culture or other moderating factors.

Second, although there is still a dearth of studies demonstrating how charisma affects macro-organizational performance (in terms of productivity measures, assets, etc.), we do know 
that charisma matters whether using subjective or objective measures of leader success and this on various levels of analysis (but mostly on the micro-level). Third, is charisma-like intelligence, or a confident and extraverted personality — a gift? If it is, that charisma matters for performance suggests it is critical to have appropriate leaders in place by using well-designed selection systems. However, as suggested by Etzioni (1961) decades ago, charisma can be trained and it is encouraging to see that there are scientific studies demonstrating this point (Antonakis et al 2011, Frese et al 2003, Towler 2003). Such studies have shown that leaders can be made aware of different signaling techniques, both verbal (e.g., use of metaphor, contrasts, stating the sentiments of the collective) and nonverbal (e.g., gesturing, facial expressions), that can be used to make the leaders more charismatic. Also, the gains that can be made are quite respectable, with a $d=.62$ (e.g., see Antonakis et al 2011). Thus, charisma is a "gift" in the sense that leaders can receive it via well designed interventions! However, these interventions cannot be done in a cursory manner (Antonakis et al 2011).

As concerns leader development efforts, there is far too much fad-driven thinking in the world of practice (Zaccaro \& Horn 2003); why precisely this is the case is anybody's guess but it probably has to do with commercial interests of consulting companies, self-proclaimed gurus, lack of scientific training among practitioners, but also from badly designed and insufficiently tested leadership models emanating from the world of academia that works its way into practice. As concerns the latter, immensely popular book authors (e.g., of "Good-to-great” or "Built-tolast" type books), after having studied successful companies, suggested that charisma does not matter for organizational performance. Such books, however, are based on very faulty logic and statistics, including (a) what is commonly referred to as sampling on the dependent variablethat is, assuming what successful cases have in common drives their success without having compared these cases to a control group (Denrell 2003) — or (b) regression to the mean 
(Kahneman 2011), a statistical phenomenon explaining why successful performance can depend on luck or random causes and with time it will regress back to mediocrity. Thus, it is very important for practitioners, but also academicians too, to critically examine whether the interventions they are using are evidence-based (Dietz et al 2014).

To conclude, leadership and in particular its charismatic form is very important for teams, organizations, even countries. Moreover, charismatic leaders can be formal or informal: charisma can be exhibited across all levels of institutions, from supervisors to team players in leaderless teams, all the way up to CEO or country presidents; it can also be exhibited in social movements and can work from close or a distance. Thus, what we have described is not a phenomenon that is uniquely linked to a position; it is a process of influence. As such, it is imperative that institutions find ways to identify and develop this process, and then to harness it for the greater good.

\section{Conclusions}

In this review, we showed how thinking on charisma has developed over time. Contrasting various literatures, we showed how charisma has gone from being conceived as a rather unknown and apparently divine quantity whose nature was revolutionary to a more domesticated version that can be observed in various settings and operationalized to predict various outcomes. We showed that some of the biggest obstacles the charisma construct has faced included the lack of proper definition of charisma, the confounding of charisma with transformational leadership, and the very lax, and endogeneity-plagued standards that have been used to measure and model charisma. We hope that our review has helped clear the way to developing a unified theory of charisma so that it can be studied it in a more robust and causallydefensible way. 


\section{Summary points}

1. Charisma continues to occupy a prominent role in leadership research.

2. The early literature on charisma was very vague about the nature of construct.

3. The two major streams of charisma, which conceptualize charisma in rather different ways include (a) sociology and political science and (b) applied psychology and management.

4. Charisma is often confused with transformational leadership; these are separate constructs and charisma should be studied in its own right.

5. Many definitions of charisma have been tautological or unclear; it is best to think of charisma from a signaling theory point of view.

6. Given the limitations of questionnaire measures, biases of raters, and other endogeneity biases, charisma must be measured and operationalized in an objective way when used as an independent variable.

7. There is a need to study the impact of charisma on objective outcomes and using strong causal designs.

8. Charisma can be developed.

\section{Related resources}

The following TEDx talk, delivered by the first author of the study, demonstrates the importance of charisma. This resource could be a useful complement in education and training: https://youtu.be/SEDvD1IICfE 


\section{References}

Antonakis J. 2012. Transformational and Charismatic Leadership. In The nature of leadership, ed. DV Day, J Antonakis, pp. 256-88. Thousand Oaks: Sage Publications

Antonakis J, Atwater LE. 2002. Leader distance: A review and a proposed theory. The Leadership Quarterly 13: 673-704

Antonakis J, Avolio BJ, Sivasubramaniam N. 2003. Context and leadership: An examination of the nine-factor full-range leadership theory using the Multifactor Leadership Questionnaire. The Leadership Quarterly 14: 261-95

Antonakis J, Bastardoz N, Liu Y, Schriesheim CA. 2014a. What makes articles highly cited? The Leadership Quarterly 25: 152-79

Antonakis J, Bendahan S, Jacquart P, Lalive R. 2010. On making causal claims: A review and recommendations. The Leadership Quarterly 21: 1086-120

Antonakis J, Bendahan S, Jacquart P, Lalive R. 2014b. Causality and endogeneity: Problems and solutions. In The Oxford Handbook of Leadership and Organizations, ed. DV Day, pp. 93-117. New York: Oxford University Press

Antonakis J, Fenley M, Liechti S. 2011. Can Charisma Be Taught? Tests of Two Interventions. The Academy of Management Learning and Education 10: 374-96

Antonakis J, Fenley M, Liechti S. 2012. Learning charisma: Transform yourself into someone people want to follow. Harvard Business Review June: 127-30

Antonakis J, House RJ. 2014. Instrumental leadership: Measurement and extension of transformational-transactional leadership theory. The Leadership Quarterly 25: 746-71

Aristotle, Butcher SH. 2011. Poetics: CreateSpace

Aristotle, Roberts WR, Bywater I, Solmsen F. 1954. Rhetoric. New York,: Modern Library

Awamleh R, Gardner WL. 1999. Perceptions of leader charisma and effectiveness: The effects of vision content, delivery, and organizational performance. The Leadership Quarterly 10: 345-73

Bacharach SB. 1989. Organizational theories: Some criteria for evaluation. Academy of Management Review 14: 496-515

Barraza JA, Alexander V, Beavin LE, Terris ET, Zak PJ. 2015. The heart of the story: Peripheral physiology during narrative exposure predicts charitable giving. Biological Psychology 105: $138-43$

Barraza JA, Zak PJ. 2009. Empathy toward Strangers Triggers Oxytocin Release and Subsequent Generosity. Annals of the New York Academy of Sciences 1167: 182-89

Bascle G. 2008. Controlling for endogeneity with instrumental variables in strategic management research. Strategic Organization 6: 285-327

Bass BM. 1985. Leadership and performance beyond expectations. New York: The Free Press

Bass BM. 1990. Bass \& Stogdill's handbook of leadership: Theory, research, and managerial applications. New York: Free Press. xv, 1182 p. pp.

Bass BM, Avolio BJ. 1995. MLQ Multifactor leadership questionnaire for research: Permission set. Redwood City, CA: Mindgarden

Bensman J, Givant M. 1975. Charisma and modernity: The use and abuse of a concept. Social research: $570-614$

Berlew DE. 1974. Leadership and organizational excitement. California Management Review 17: 21-30

Beyer JM. 1999. Taming and promoting charisma to change organziations. The Leadership Quarterly 10: 307-30 
Bligh MC, Kohles JC, Meindl JR. 2004. Charisma under crisis: Presidential leadership, rhetoric, and media responses before and after the september 11th terrorist attacks. The Leadership Quarterly 2: 211-39

Bollen KA. 2012. Instrumental Variables in Sociology and the Social Sciences. Annual Review of Sociology 38: 37-72

Bono JE, Judge TA. 2004. Personality and Transformational and Transactional Leadership: A Meta-Analysis. Journal of Applied Psychology 89: 901-10

Bouchard TJ, Loehlin JC. 2001. Genes, evolution, and personality. Behavior Genetics 31: 243-73

Bouchard TJ, McGue M. 2003. Genetic and environmental influences on human psychological differences. Journal of Neurobiology 54: 4-45

Brodbeck FC, Frese M, Akerblom S, Audia G, Bakacsi G, et al. 2000. Cultural ariation of Leadership Prototypes Across 22 European Countries. Journal of Occupational and Organizational Psychology 73: 1-73

Brown DJ, Lord RG. 1999. The utility of experimental research in the study of transformational/charismatic leadership. The Leadership Quarterly 10: 531-39

Bryman A. 1992. Charisma and leadership in organizations. London: Sage Publications

Burns JM. 1978. Leadership. New York: Harper \& Row

Cantor N, Mischel W. 1977. Traits as prototypes: Effects on recognition memory. Journal of Personality and Social Psychology 35: 38-48

Conger JA. 1998. Qualitative research as the cornerstone methodology for understanding leadership. The Leadership Quarterly 9: 107-21

Conger JA, Kanungo RN. 1987. Toward a behavioral theory of charismatic leadership in organizational settings. Academy of Management Review 12: 637-47

Conger JA, Kanungo RN, eds. 1988. Charismatic leadership: The elusive factor in organizational effectiveness. San Francisco: Jossey-Bass Publishers

Conger JA, Kanungo RN. 1998. Charismatic leadership in organizations. Thousand Oaks, CA: Sage Publications.

Conger JA, Kanungo RN, Menon ST. 2000. Charismatic Leadership and follower effects. Journal of Organizational Behavior 21: 747-67

Davies JC. 1954. Charisma in the 1952 Campaign. American Political Science Review 48: 1083102

Davis KM, Gardner WL. 2012. Charisma under crisis revisited: Presidential leadership, perceived leader effectiveness, and contextual influences. The Leadership Quarterly 23: 918-33

Day DV. 2000. Leadership development: A review in context. The Leadership Quarterly 11: 581-613

Day DV. 2012. The future of leadership: Challenges and prospects. In The Oxford Handbook of Leadership and Organizations, ed. DV Day, pp. 853-61. New York: Oxford

Day DV, Antonakis J. 2013. The future of leadership In The Wiley-Blackwell Handbook of the Psychology of Leadership, Change and Organizational Development, ed. HS Leonard, R Lewis, AM Freedman, J Passmore, pp. 221-35. Oxford: John Wiley \& Sons

Day DV, Fleenor JW, Atwater LE, Sturm RE, McKee RA. 2014. Advances in leader and leadership development: A review of 25 years of research and theory. The Leadership Quarterly 25: 63-82

De Cremer D, Van Knippenberg D. 2004. Leader self-sacrifice and leadership effectiveness: The moderating role of leader self-confidence. Organizational Behavior and Human Decision Processes 95: 140-55 
DeGroot T, Kiker DS, Cross TC. 2000. A Meta-Analysis to Review Organizational Outcomes Related Charismatic Leadership. Canadian Journal of Administrative Sciences 17: 356-72

Den Hartog DN, House RJ, Hanges PJ, Ruiz-Quintanilla SA. 1999. Culture specific and crossculturally generalizable implicit leadership theories: Are attributes of charismatic/transformational leadership universally endorsed? The Leadership Quarterly 10: $219-56$

Den Hartog DN, Verburg RM. 1997. Charisma and rhetoric: Communicative techniques of international business leaders. The Leadership Quarterly 8: 355-91

Denrell J. 2003. Vicarious learning, undersampling of failure, and the myths of management. Organization Science 14: 227-43

Dietz J, Antonakis J, Hoffrage U, Krings F, Marewski J, Zehnder C. 2014. Teaching evidencebased management with a focus on producing local evidence. Academy of Management Learning \& Education 13: 397-414

Downton JV. 1973. Rebel leadership: Commitment and charisma in the revolutionary process. New York: The Free Press

Duncan GJ, Magnusson KA, Ludwig J. 2004. The Endogeneity Problem in Developmental Studies. Research in Human Development 1: 59-80

Eagly AH, Antonakis J. 2014. Leadership. In APA Handbook of Personality and Social Psychology: Attitudes and Social Cognition, ed. G Borgida, J Bargh, pp. 571-92. Washington: APA Books

Eisenhardt KM, Graebner ME. 2007. Theory building from cases: Opportunities and challenges. Academy of Management Journal 50: 25-32

Emrich CG, Brower HH, Feldman JM, Garland H. 2001. Images in words: Presidential rhetoric, charisma, and greatness. Administrative Science Quarterly 46: 527-57

Endler NS, Magnusson D. 1976. Toward an interactional psychology of personality. Psychological Bulletin 83: 956

Erickson DJ, Krull DS. 1999. Distinguishing Judgments About What From Judgments About Why: Effects of Behavior Extremity on Correspondent Inferences and Causal Attributions. Basic and Applied Social Psychology 21: 1-11

Etzioni A. 1961. A comparative analysis of complex organizations. New York: The Free Press

Etzioni A. 1964. Modern organizations. Englewood Cliffs, New Jersey: Prentice-Hall

Fanelli A, Misangyi VF, Tosi HL. 2009. In Charisma We Trust: The Effects of CEO Charismatic Visions on Securities Analysts. Organization Science 20: 1011-33

Fiedler FE. 1967. A theory of leadership effectiveness. New York: McGraw-Hill

Fleishman EA. 1953. The Measurement of Leadership Attitudes in Industry. Journal of Applied Psychology 37: 153-58

Flynn FJ, Staw BM. 2004. Lend me your wallets: The effect of charismatic leadership on external support for an organization. Strategic Management Journal 25: 309-30

Frese M, Beimel S, Schoenborn S. 2003. Action training for charismatic leadership: Two evaluations of studies of a commercial training module on inspirational communication of a vision. Personnel Psychology 56: 671-97

Friedland WH. 1964. For a sociological concept of charisma. Social Forces 43: 18-26

Friedrich CJ. 1961. Political Leadership and the Problem of the Charismatic Power. Journal of Politics 23: 3-24

Fuller JB, Patterson CEP, Hester K, Stringer DY. 1996. A quantitative review of research on charismatic leadership. Psychological Reports 78: 271-87 
Gardner WL, Avolio BJ. 1998. The charismatic relationship: A dramaturgical perspective. Academy of Management Review 23: 32-58

Gardner WL, Lowe KB, Moss TW, Mahoney KT, Cogliser CC. 2010. Scholarly Leadership of the Study of Leadership: A Review of The Leadership Quarterly's Second Decade, 20002009. The Leadership Quarterly 12: 922-58

Gemmill G, Oakley J. 1992. Leadership: An Alienating Social Myth? Human Relations 45: 11329

Greene CN. 1977. Disenchantment with leadership research: Some causes, recommendations, and alternative directions. In Leadership: The cutting edge. , ed. JG Hunt, LL Larson, pp. 57-67. Carbondale: Southern Illinois University Press

Hamstra MRW. 2014. 'Big' men: Male leaders' height positively relates to followers' perception of charisma. Personality and Individual Differences 56: 190-92

Hermalin BE. 1998. Toward an Economic Theory of Leadership: Leading by Example. The American Economic Review 88: 1188-206

Hogg MA. 2001. A social identity theory of leadership. Personality \& Social Psychology Review 5: $184-200$

House RJ. 1977. A 1976 Theory of Charismatic Leadership. In The Cutting Edge, ed. JG Hunt, LL Larson, pp. 189-207. Carbondale: Southern Illinois: University Press

House RJ. 1999. Weber and the Neo-charismatic Leadership Paradigm: A Response to Beyer. The Leadership Quarterly 10: 563-74

House RJ, Howell JM. 1992. Personality and charismatic leadership. The Leadership Quarterly 3: $81-108$

House RJ, Spangler WD, Woycke J. 1991. Personality and charisma and the U.S. presidency: A psychological theory of leader effectiveness. Administrative Science Quarterly 36: 364-96

Howell JM. 1988. Two faces of charisma: Socialized and personalized leadership in organizations. In Charismatic leadership: The elusive factor in organizational effectiveness, ed. JA Conger, RN Kanungo, pp. 213-36. San Francisco: Jossey-Bass Publishers

Howell JM, Frost PJ. 1989. A laboratory study of charismatic leadership. Organizational Behavior and Human Decision Processes 43: 243-69

Hunt JG. 1991. Leadership: A new synthesis. Newbury Park, CA: Sage Publications

Hunt JG. 1999. Tranformational/charismatic leadership's transformation of the field: An historical essay. The Leadership Quarterly 10: 129-44

Jacquart P, Antonakis J. 2015. When does charisma matter for top-level leaders? Effect of attributional ambiguity. Academy of Management Journal 58

Kahneman D. 2011. Thinking, fast and slow. New York: Farrar, Straus and Giroux. 499 p. pp.

Katz D, Maccoby N, Gurin G, Floor LG. 1951. Productivity, supervision and morale among railroad workers. Ann Arbor, Michigan: Survey Research Center, Institute for Social Research (University of Michigan)

Koopman PL, Den Hartog D, Konrad E, Akerblom S, Audia G, et al. 1999. National Culture and Leadership Profiles in Europe: Some Results From the GLOBE Study. European Work and Organizational Psychology 8: 503-20

Kosloff S, Greenberg J, Weise D, Solomon S. 2010. The effects of mortality salience on political preferences: The roles of charisma and political orientation. Journal of Experimental Social Psychology 46: 139-45

Lakoff G, Johnson M. 1980. Metaphors we live by. Chicago: University of Chicago Press. xiii, 242 p. pp. 
Larcker DF, Rusticus TO. 2010. On the use of instrumental variables in accounting research. Journal of Accounting and Economics 49: 186-205

Lord RG, Binning JF, Rush MC, Thomas JC. 1978. The effect of performance cues and leader behavior on questionnaire ratings of leadership behavior. Organizational Behavior and Human Performance 21: 27-39

Lord RG, Foti RJ, De Vader CL. 1984. A Test of Leadership Categorization Theory: Internal Structure, Information Processing, and Leadership Perceptions. Organizational Behavior and Human Performance 34: 343-78

Lowe KB, Gardner WL. 2000. Ten Years of the Leadership Quarterly: Contributions and Challenges for the Future. The Leadership Quarterly 11: 459-514

MacKenzie SB. 2003. The dangers of poor construct conceptualization. Journal of the Academy of Marketing Science 31: 323-26

Maclachlan B. 1996. The Age of Grace: Charis in Early Greek Poetry. Chichester: Princeton Maxwell JA. 2010. Using Numbers in Qualitative Research. Qualitative Inquiry 16: 475-82

Meindl JR, Ehrlich SB. 1987. The romance of leadership and the evaluation of organizational performance. Academy of Management Journal 30: 91-109

Miner JB. 1975. The uncertain future of the leadership concept. An overview. In Leadership Frontiers, ed. JG Hunt, LL Larson, pp. 197-208. Kent, OH: Kent State University

Mio JS, Riggio RE, Levin S, Reese R. 2005. Presidential leadership and charisma: The effects of metaphor. The Leadership Quarterly 16: 287-94

Mount MK, Scullen SE. 2001. Multisource feedback ratings: What do they really measure? In How people evaluate others in organizations, ed. M London, pp. 155-76. Mahwah, NJ: Lawrence Erlbaum

Mumford MD, Antes AL, Caughron JJ, Friedrich TL. 2008. Charismatic, ideological, and pragmatic leadership: Multi-level influences on emergence and performance. The Leadership Quarterly 19: 144-60

Podsakoff NP, Podsakoff PM, MacKenzie SB, Klinger RL. 2013. Are we really measuring what we say we're measuring? Using video techniques to supplement traditional construct validation procedures. Journal of Applied Psychology 98: 99-113

Riesebrodt M. 1999. Charisma in Max Weber's Sociology of Religion. Religion 29: 1-14

Scullen SE, Mount MK, Goff M. 2000. Understanding the latent structure of job performance ratings. Journal of Applied Psychology 85: 956-70

Shamir B. 1995. Social Distance and Charisma - Theoretical Notes and an Exploratory-Study. The Leadership Quarterly 6: 19-47

Shamir B. 1999. Taming charisma for better understanding and greater usefulness: A response to beyer. The Leadership Quarterly 10: 555-62

Shamir B, Arthur MB, House RJ. 1994. The rhetoric of charismatic leadership: A theoretical extension, a case study, and implications for research. The Leadership Quarterly 5: 25-42

Shamir B, House RJ, Arthur MB. 1993. The motivational effects of charismatic leadership: A self-concept based theory. Organization Science 4: 577-94

Shamir B, Howell JM. 1999. Organizational and contextual influences on the emergence and effectiveness of charismatic leadership. The Leadership Quarterly 10: 257-83

Shamir B, Zakay E, Breinin E, Popper M. 1998. Correlates of charismatic leader behavior in military units: Subordinates' attitudes, unit characteristics, and superiors' appraisals of leader performance. Academy of Management Journal 41: 387-409

Shils E. 1965. Charisma, Order, and Status. American Sociological Review 30: 199-213 
Silvia PJ, Beaty RE. 2012. Making creative metaphors: The importance of fluid intelligence for creative thought. Intelligence 40: 343-51

Simonton DK. 1988. Presidential style: Personality, biography, and performance. Journal of Personality and Social Psychology 55: 928-36

Simonton DK. 2003. Qualitative and Quantitative Analyses of Historical Data. Annual Review of Psychology 54: 617-40

Smith DN. 1998. Faith, reason, and charisma: Rudolf Sohm, Max Weber, and the theology of grace. Sociological Inquiry 68: 32-60

Sohm R. 1892. Kirchenrecht: Verlag von Duncker \& Humblot

Speer NK, Reynolds JR, Swallow KM, Zacks JM. 2009. Reading Stories Activates Neural Representations of Visual and Motor Experiences. Psychological Science 20: 989-99

Spence M. 2002. Signaling in Retrospect and the Informational Structure of Markets. The American Economic Review 92: 434-59

Spencer ME. 1973. What is charisma? British Journal of Sociology 24: 341-54

Stogdill RM. 1963. Manual for the Leader Behavior Description Questionnaire, Form XII. Columbus, OH: Fisher College of Business: The Ohio State University.

Sturm RE, Antonakis J. 2015. Interpersonal Power: A Review, Critique, and Research Agenda. Journal of Management 41: 136-63

Todorov A, Mandisodza AN, Goren A, Hall CC. 2005. Inferences of competence from faces predict election outcomes. Science 308: 1623-26

Towler AJ. 2003. Effects of charismatic influence training on attitudes, behavior, and performance. Personnel psychology 56: 363 - 81

Trichas S, Schyns B. 2012. The face of leadership: Perceiving leaders from facial expression. The Leadership Quarterly 23: 545-66

Tsai W, Wu C-H. 2010. Knowledge combination: A cocitation analysis. Academy of Management Journal 53: 441-50

Tucker RC. 1968. The theory of charismatic leadership. Daedalus 97: 731-56

Van Knippenberg B, Van Knippenberg D. 2005. Leader self-sacrifice and leadership effectiveness: the moderating role of leader prototypicality. Journal of Applied Psychology 90: 25

van Knippenberg D, Sitkin SB. 2013. A Critical Assessment of Charismatic-Transformational Leadership Research: Back to the Drawing Board? The Academy of Management Annals 7: $1-60$

Waldman DA, Balthazard PA, Peterson SJ. 2011. Leadership and Neuroscience: Can We Revolutionize the Way That Inspirational Leaders Are Identified and Developed? Academy of Management Perspectives 25: 60-74

Waldman DA, Yammarino FJ. 1999. CEO charismatic leadership: Levels-of-management and levels-of-analysis effects. Academy of Management Review 24: 266-85

Weber M. 1947. The theory of social and economic organization. New York: The Free Press

Weber M. 1968. Max Weber on charisma and institutional building (Ed. S. N. Eisenstadt). Chicago: The University of Chicago Press

White HD, Griffith BC. 1981. Author cocitation: A literature measure of intellectual structure. Journal of the American Society for information Science 32: 163-71

Willner AR. 1984. The spellbinders: Charismatic political leadership. New Haven: CT.: Yale University Press

Wowak AJ, Mannor MJ, Arrfelt M, McNamara G. 2014. Earthquake or glacier? How CEO Charisma Manifests In Firm Strategy Over Time. Strategic Management Journal 
xxxxxxx. in press. Archival Data in Micro-Organizational Research: A Toolkit for Moving to a Broader Set of Topics". Journal of Management

Yukl GA. 1999. An evaluation of conceptual weaknesses in transformational and charismatic leadership theories. The Leadership Quarterly 10: 285-305

Zaccaro SJ, Horn ZNJ. 2003. Leadership theory and practice: Fostering an effective symbiosis. The Leadership Quarterly 14: 769-806 
Figure 1A: The core of the intellectual landscape of the socio-scientific study of charisma

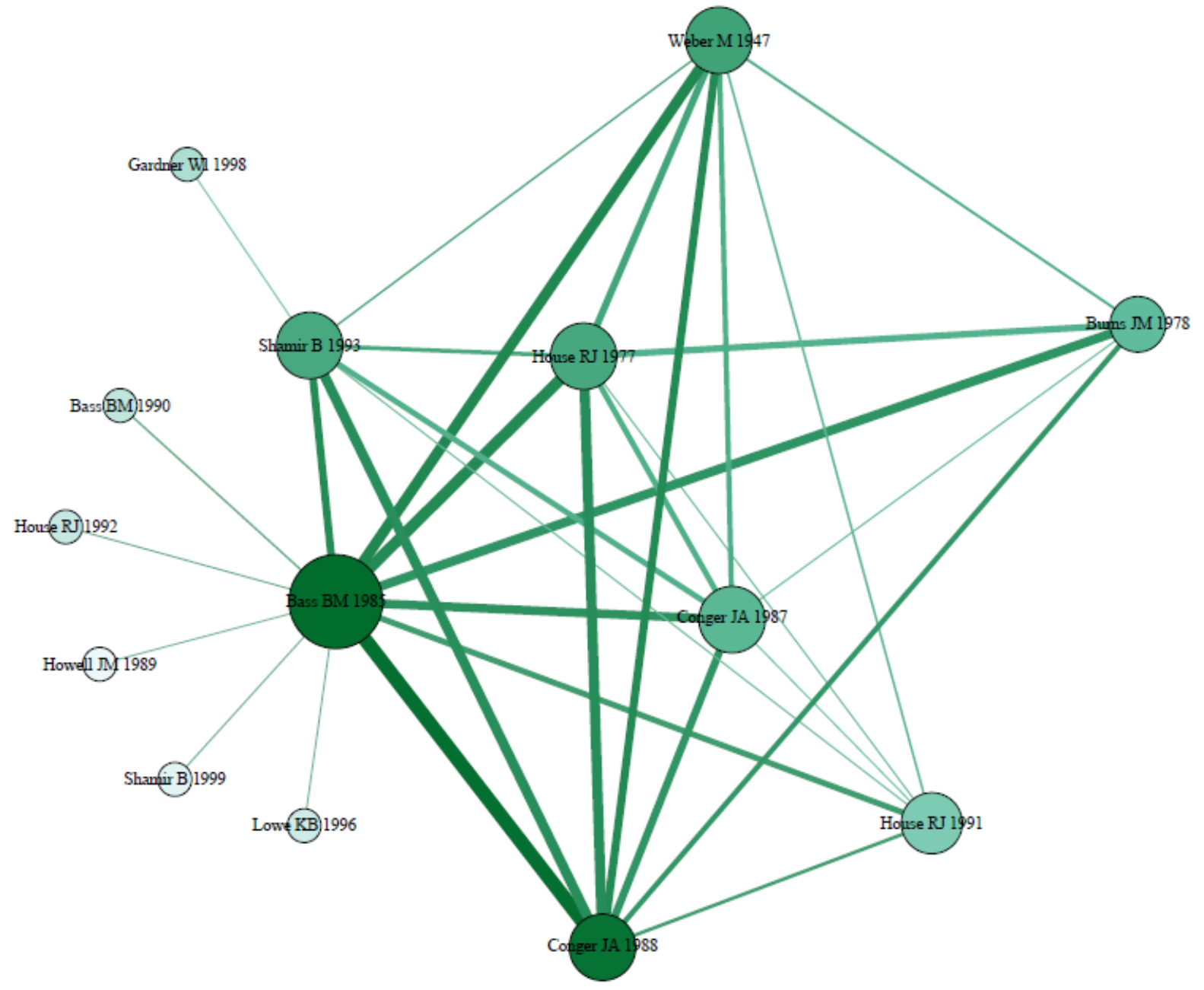

Note: This document co-citation network map shows up to $.10 \%$ most co-cited works within the overall co-citation network derived from the 280 articles analyzed in the review. Each node represents one document (only first authors are named) and edges represent the co-citations of two documents. Darker and thicker edges indicate more co-citations. Node size indicates the number of other documents along which this node is co-cited (i.e., its degree), and darker color indicates greater strength (where strength is the sum of the weights of all edges to which a node is connected). An interactive version of this network can be accessed online at the following address: http://www.hec.unil.ch/jantonakis/annualreviews/index.html 


\section{Figure 1B: An author co-citation map of the socio-scientific study of charisma}

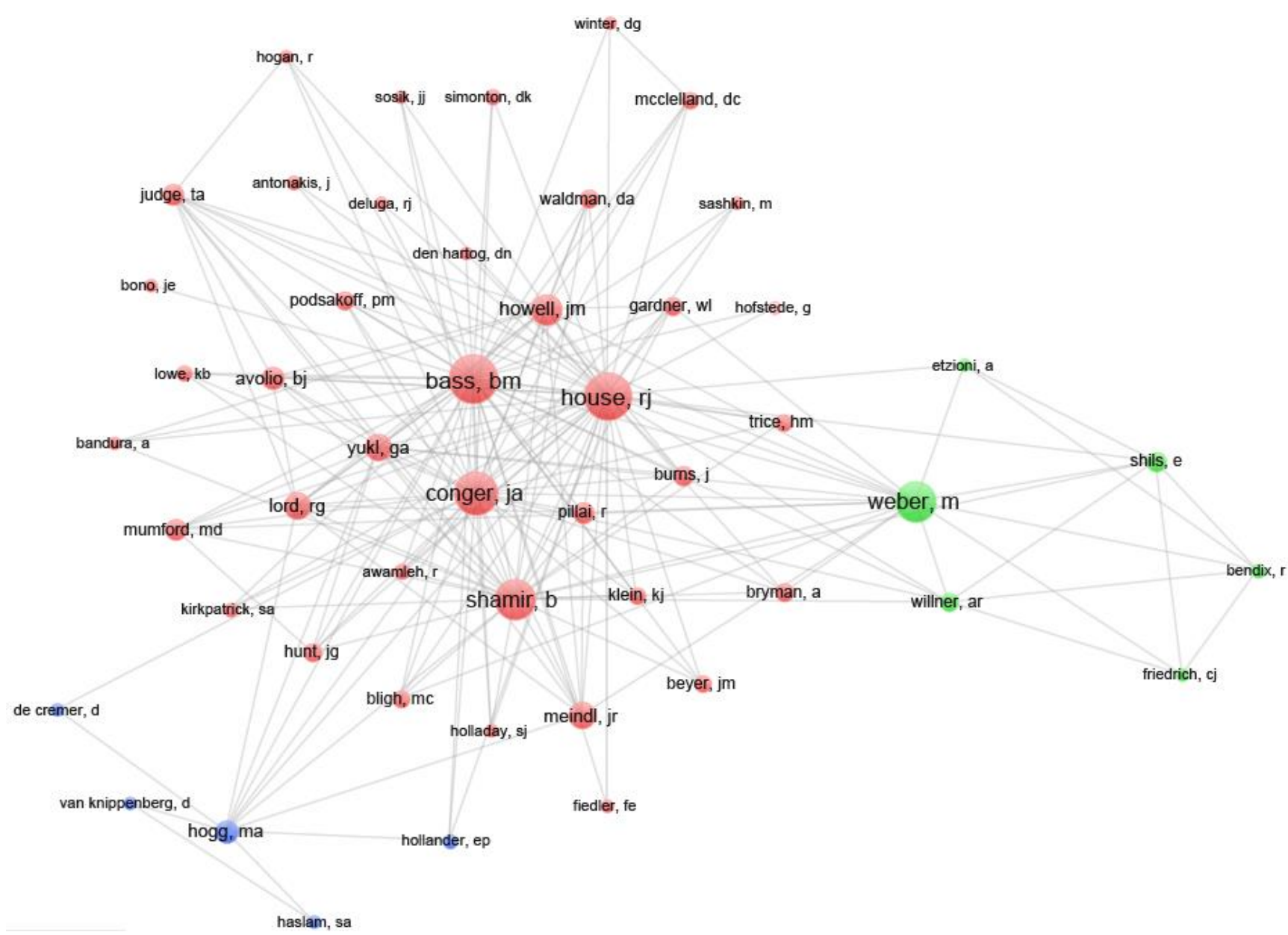

Note: This co-citation map is based on first authors only. Difference in node size indicates relative difference in the frequency of occurrence. Sources that are frequently co-cited are positioned close to each other. Only the 200 strongest edges are represented here. Node color indicates membership to a common densely connected cluster, as identified by an algorithm. This figure also distinguishes discipline clusters (a) sociology and political science (green nodes), (b) applied psychology and management (red nodes), and (c) social psychology (blue nodes). 
Figure 2: Publishing Trends: Number of articles using the term "charisma" or variants

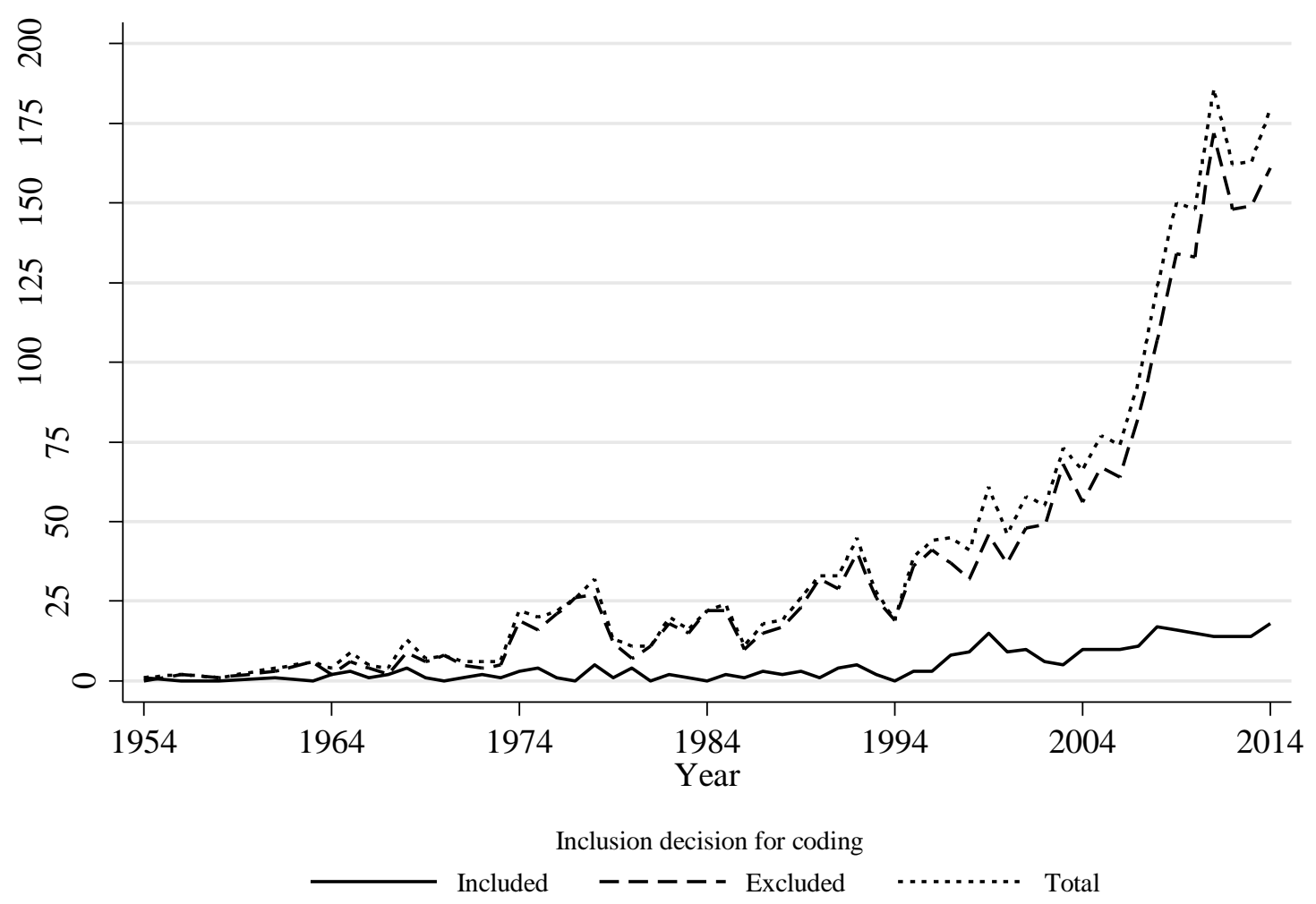

Note: We searched for articles using the term charisma and all combinations thereof in the Web of Science, published in 2014 or before. The search returned 2,438 articles of which we included 280 (see Figure 2). We excluded articles not discussing charisma per se or only tackling it cursorily. We excluded articles not written in English, book reviews, focusing on non-human charisma, scaledevelopment and testing articles, commentaries, editorials, book chapters, and conference abstracts. We excluded quantitative articles and meta-analyses using an endogenous measure of charisma as an independent variable, moderator or mediator, and failing to "instrument" charisma correctly (Antonakis et al 2010). For details on the coding refer to the online Supplementary Material. 


\section{Table 1: Definitions of Charisma}

Element of definition

Percentage of definitions

Percentage of

Useful

using attribute

definitions

for a

(weighted)

using attribute

definition?

(unweighted)

1 Quality, ability, gift of the leader

$\begin{array}{rrr}84.95 & 71.43 & \text { No } \\ 62.37 & 28.57 & \text { No } \\ 22.58 & 42.86 & \text { No } \\ 15.05 & 28.57 & \text { Yes } \\ 13.98 & 18.37 & \text { No } \\ 11.83 & 22.45 & \text { No } \\ 8.60 & 16.33 & \text { No } \\ 8.60 & 16.33 & \text { Yes } \\ 8.60 & 16.33 & \text { No } \\ 7.53 & 14.29 & \text { No } \\ 6.45 & 12.24 & \text { Yes } \\ 6.45 & 12.24 & \text { No } \\ 4.30 & 8.16 & \text { No }\end{array}$

2 Exceptional, extraordinary, exemplary individual

3 Defined in terms of an outcome

4 Vision, ideology, values, morals, beliefs, mission, symbols of leader

5 Followers' attribution (including group prototypicality of leader)

6 Social process (interaction, relationship)

7 Divine related

8 Emotion-based

9 Leader's behaviors and actions

10 Followers' characteristics (need, motives, background, self-esteem)

11 Expressive communication

12 Any contextual circumstances (crisis, social situation)

13 Leader trait (e.g., self-confidence, persistence, passion, optimism, honest, reliable)

4.30

8.16

No

Note: The weighted data uses 93 articles as the unit of analysis, some of which used the same definition. That is (a) 41 articles used the definition "a certain quality of an individual personality by virtue of which he is set apart from ordinary men and treated as endowed with supernatural, superhuman, or at least specifically exceptional powers or qualities" (coded under categories 1 and 2), and (b) 5 articles used the definition "An extraordinary quality of a person, regardless of whether this quality is actual, alleged, or presumed" (coded under categories 1, 2, and 5). The unweighted data uses the definition as the unit of analysis. 


\section{Appendix}

Endogeneity is an undesirable property of an estimator that renders estimates inconsistent, and such estimates do not capture the causal relation between variables and hence cannot inform policy (for a detailed introduction to the problem, see: Antonakis et al 2010, Antonakis et al 2014b). Inconsistent estimates do not converge to the true population values, asymptotically (i.e., as the sample increases). An endogenous variable is one that depends on other variables. Exogenous variables - for example, a manipulated variables in an experiment, variables that vary naturally in nature (e.g., temperature), are fixed by some process (e.g., latitude), are heritable to a large extent or fixed in adulthood (e.g., intelligence and personality), are cyclical (e.g., election cycles) and so forth - cannot vary as a function of other variables in or omitted from a model. However, an endogenous variable is caused by other variables (i.e., $q$ ); if those variables are omitted from the model but correlate with the outcome (i.e., $y$ ) that the endogenous variable (i.e., $x$ ) is supposed to predict, the coefficient of $x$ on $y$, that is, the ordinary least squares (OLS) or maximum likelihood (ML) estimate, $\frac{\operatorname{Cov}(y, x)}{\operatorname{Var}(x)}$, cannot be interpreted and will be confounded; this confounding depends on the strength and direction of the relation of $q$ to $y$ and $q$ to $x$ (Antonakis et al 2010). Endogenous variables can be used as regressors only if they have been "instrumented"- that is, an exogenous source of variance $(z)$ is used to purge the estimate from endogeneity bias in a model of the form $z \rightarrow x \rightarrow y$. Note, this mediation model cannot be estimated using the "usual" mediation methods in the organization sciences, whether bootstrapped or not; an instrumental variable estimator must be used to estimate this model. Because $z$ is exogenous, it will not vary as a function of omitted causes of $y$ or $x$; thus the instrumental variable estimate, $\frac{\operatorname{Cov}(y, z)}{\operatorname{Cov}(x, z)}$, whether estimated by two-stage least squares (2SLS) or maximum likelihood (where cross equation disturbances of $x$ and $y$ are correlated, see Antonakis et al 2010) will be consistent and capture the true effect of $x$ on $y$ (Bollen 2012). To the extent that $x$ is a true cause of $y$-and as the instrumental variable formula shows $-z$ must correlate both with $y$ and with $x$. 


\title{
On-line supplementary materials
}

\section{Charisma: An ill-defined and ill-measured gift}

\author{
John Antonakis \\ Department of Organizational Behavior \\ University of Lausanne \\ john.antonakis@unil.ch \\ Nicolas Bastardoz \\ Department of Organizational Behavior \\ University of Lausanne \\ nicolas.bastardoz@unil.ch \\ Philippe Jacquart \\ EM-LYON Business School \\ jacquart@em-lyon.com \\ Boas Shamir \\ Department of Sociology and Anthropology \\ The Hebrew University of Jerusalem
}




\section{Contents}

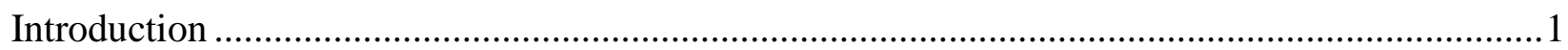

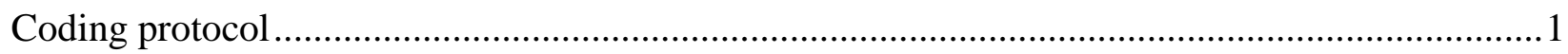

Which types of articles have had the biggest impact? ..................................................... 3

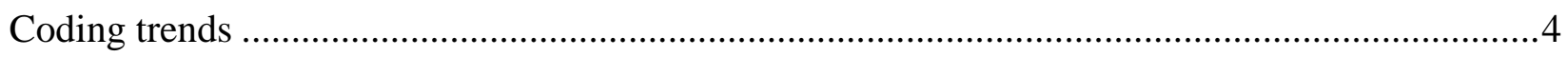

For the correlation matrix of the key variables in coded papers, refer to Table $13 . \ldots \ldots \ldots \ldots \ldots \ldots \ldots . . . . .7$

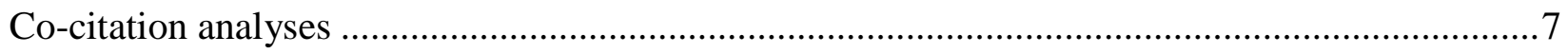

Table 1: Predicting Citations by Article Type ................................................................ 10

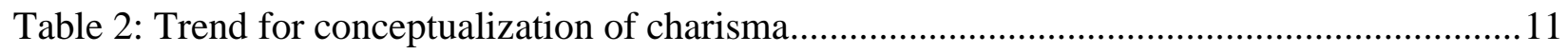

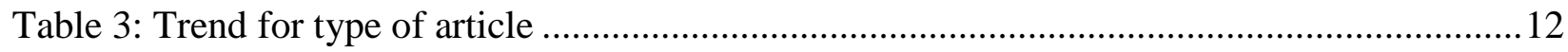

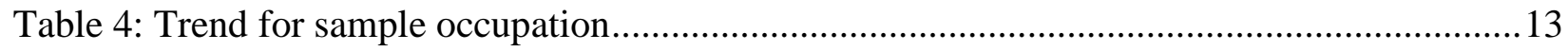

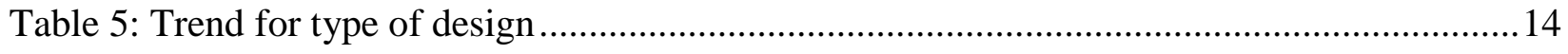

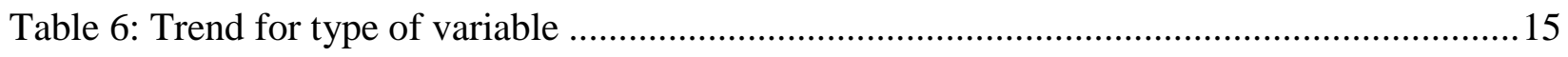

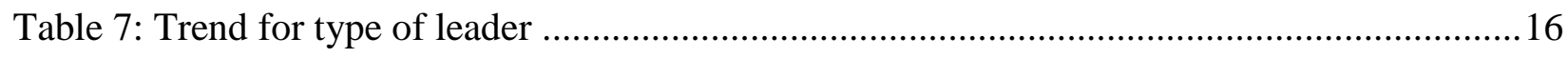

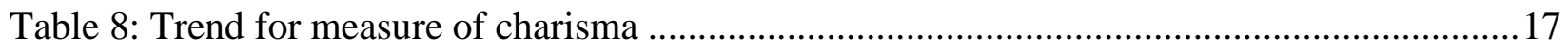

Table 9: Trend for use of MLQ and other measures ..................................................... 18

Table 10: Trend for location of the sample .................................................................. 19

Table 11: Trend for design of qualitative studies............................................................20

Table 12: Qualitative articles location of the sample ........................................................21

Table 13: Correlation matrix of key variables in coded papers ...........................................22

Figure 1A: The intellectual landscape of the socio-scientific study of charisma........................23

Figure 1B: The intellectual landscape of the socio-scientific study of charisma .......................24

Figure 2: Source co-citation analysis of the socio-scientific study of charisma ........................25

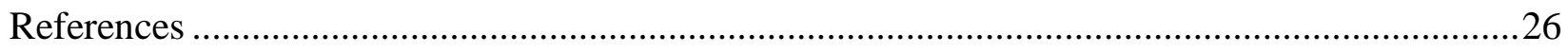




\section{Introduction}

In this document, we present details on the coding protocol we used, coder reliability, as well as results and trends we uncovered from the features we coded from articles. We also discuss the co-citation analysis more extensively and present additional results.

\section{Coding protocol}

We developed a coding manual based on discussions between the authors about relevant features to be extracted from the articles. The coding categories were refined after numerous rounds of discussion following the coding of a sample of papers. We trained two graduate students to undertake the coding. From the 280 articles that had to be coded ${ }^{1}$, we first used 54 articles as training materials and each of these articles was independently coded by the graduate students. We also used this initial phase to refine the coding variables and categories. The first and second author of the article resolved inconsistencies between the coders. In the second phase, each coder was assigned 113 articles to code. Once completed, we gave each coder a set of 20 randomly determined articles previously coded by the other coder to compute the kappa statistic. These 40 articles generated 422 coding events. The coders agreed on $87.44 \%$ of the coding events. The agreement that could have been expected due to chance would have been $24.11 \%$. Thus, the agreement statistic (Landis \& Koch 1977), $\kappa=.83, S E=.02, z=34.31, p<.001$, indicated that agreement was above chance.

\footnotetext{
${ }^{1}$ Important to note is that there were substantially more quantitative articles in the initial pool (210 articles altogether); however, we discarded 98 articles because they did not take appropriate corrective actions with respect to using (a) the MLQ or similar measures as independent variables or (b) used MLQ-type measures as endogenous regressors (i.e., mediators). Also, although we included in this review only quantitative articles that reported unconfounded estimates when charisma was used as a regressor, and which thus may be of better quality than the other categories of articles, we did not rate qualitative articles for quality given that there are no standards for doing so. Note though that in Antonakis et al (2014) all quantitative and qualitative articles were included in the review regardless of quality, and we found the same results as they did in the present articles (i.e., that qualitative articles are undercited). There are several possibilities as to why qualitative articles are less appreciated by researchers in general, and we do not discuss these here extensively (for a discussion see Antonakis et al 2014).
} 
For each coded article, we extracted the following information:

(a) Age of article: we subtracted the year of publication from 2014;

(b) Citations: downloaded from WoS on 6 April 2015;

(c) 5-year WoS impact factor of the journal (which is highly stable: e.g., as a

demonstration, and using all journals in Applied Psychology, Business, Management, and Social Psychology, over the periods 2001-2011 gives an ICC1 > .90) or the average impact factor across the years available (coded missing for unranked journals);

(d) Information on the journal category and the impact factor of each category obtained from WoS;

(e) Author affiliations: we utilized information from a well-known ranking source (QS World University Ranking). Because rankings remain relatively stable over time (see Antonakis et al 2014), we used the average rankings over the years 2010-2014. Each affiliation got a ranking and rankings were reverse coded and averaged across coauthors for each article to obtain a collective affiliation score. Unranked universities received the lowest ranking +1 ;

(f) Number of cited references: Extracted from WoS;

(g) Article type: Categories included quantitative, qualitative, theory, and review. Note, if an article coded qualitative data quantitatively, we coded the article as quantitative; if an article made an empirical contribution, either quantitatively or qualitatively, after it had developed a theory or some propositions, it was coded as quantitative or qualitative;

(h) Definition of charisma: coded if the authors defined charisma, either in their own words or citing someone else definition of charisma.

We also looked at trends regarding some main characteristics of quantitative and, to a lesser extent, qualitative articles. The next section provides more information on the trends and the variables coded. 


\section{Which types of articles have had the biggest impact?}

We examined whether article types were associated with different citation rates, which are one of the best gauges of article impact (Bergh et al 2006, Lokker et al 2008). In order to see how the "citation market" for charisma appreciates these different modes of inquiry we modelled the citations as a function of various control variables that have been established to predict citations (see Table 3 in Antonakis et al 2014). Given that we are predicting citations across a large timespan from articles stemming from various journals and disciplines, we included the following additional controls (a) a quadratic term for article age given the "decay" of citations over time (Aksnes 2003), (b) the impact factor of the journal, given that papers published in higher impact journals typically collect more citations (Larivière \& Gingras 2010) and (c) the mean impact factor of all journals across all fields in which the journal is listed because fields have substantial different citations rates due to varying research practices (Antonakis \& Lalive 2008).

Results from a zero-inflated negative binomial model (Blevins et al 2015) showed that we could predict a hefty amount of the variance in citations, whether using lifetime citations or one that models current influence (i.e., citations per year). Looking at lifetime citations indicates that, holding constant the rest of the controls at the means, quantitative (38.13 citations), review (55.85 citations), and theory (37.87) papers all received significantly more citations than did qualitative (27.53 citations) papers. We found similar results when predicting citations per year (see Table 1).

\section{[Table 1 here]}

To supplement the above analysis on predicting citations, we also looked at the composition of the top-forty cited articles. Most used a quantitative design (i.e., 18), followed by theory papers (15), qualitative papers (4) and reviews (3); this distribution was significantly 
different (likelihood ratio $\chi^{2}(3)=17.77, p<.001$ ), as would be expected given the different proportion of coded articles. Thus, to make for a fairer comparison, in terms of proportion of articles in the top forty as a proportion of articles coded, two-tailed binomial probability tests showed that quantitative articles are overrepresented in the top-40 $(p=.09)$, as were theory papers $(p=.07)$; review articles were appropriately represented $(p>.10)$, and qualitative papers were underrepresented $(p<.01)$. These findings, coupled with the previous findings on predicting citations suggest that researchers will get more "cites for their buck" by publishing quantitative, theory or review papers on the topic of charisma.

\section{Coding trends}

In order to determine whether a trend was present in features of the coded data, we estimated robust regression models (Huber 1964), which discount outliers (using Stata 13). At first, we included the year and the year squared as regressors (we included the latter to capture possible quadratic effects). If the coefficient for the year squared was significant (at $p<.05$ ) and positive, we reported a quadratic positive trend ("++" sign in column trend). If the coefficient was not significant, we then ran a simple linear model with only year as regressor; if the latter model was significant, we reported a linear trend ("+" sign in column trend). If the regression did not converge (e.g., when there were too many zero observations), we replicated the same procedure just described above but using an OLS estimator with robust standard errors.

We will now turn to the coded variables of interest, presenting how they were coded as well as descriptions and trends.

1. The conceptualization of charisma: This category examined the perspective from which the authors conceptualized charisma, including conceptualized as (a) personality traits or combination of traits; (b) a set of leader behaviors; (c) a perception or an attribution of the leader; 
(d) attitudes, emotions or affect towards the leader; and (e) a relationship between the leader and others. Each article was classified into a single category only based on the predominant view of the author (see Table 2).

[Table 2 here]

2. Article type: Reflecting whether the article was quantitative, qualitative, theory or review (see Table 3).

[Table 3 here]

When an article was included as a quantitative piece, we coded for the following variables (note: all analyses were done at the study level):

3. Sample occupation: This variable concerned the targets of interest in the study, or put in another way, the focal entities studied in the statistical model. Categories comprised (a) managers working in private or public companies; (b) undergraduate students; (c) graduate and EMBA students; (d) politicians; and (e) others and non-specified (see Table 4).

[Table 4 here]

4. Design of the study: Here we coded the method to collect data on charisma. Relevant categories are (a) experiment, whether in laboratory, field or quasi-experiments; (b) field study; (c) archival data; and (d) coded interviews (see Table 5).

[Table 5 here]

5. How charisma was used as a variable: This variable captures how the charisma variable was included in the statistical model. Charisma was coded as being (a) an independent variable (IV); (b) a moderator; (c) a mediator; and (d) a dependent variable (DV). If a study included charisma both as an IV and as a DV, we coded for both. Note: as explained in our article, we excluded coded articles that used an endogenous measure of charisma as an IV, moderator or 
mediator, and failed to properly instrument charisma. However, when charisma was a mediator, we still included articles that would have been rejected otherwise when a hypothesis was linking the IV with charisma in a substantive manner. Only first-stage regressions were coded for these types of article (i.e., considering charisma as a DV). Articles testing charisma as a dependent variable were always included, even if the model predicting charisma was to be incorrectly tested (see Table 6).

\section{[Table 6 here]}

6. The target leader: Categories included (a) real leader I (e.g., leader with whom the rater has a direct relationship, leader under study and rated by their followers, or leader rated by the researcher from archival data); (b) real leader II (e.g., target in a video used as a stimulus material or leader with whom the follower has no direct relationship); (c) hypothetical leader (i.e., when a subject has to think of a leader, not someone in particular); and (d) actor (see Table 7).

\section{[Table 7 here]}

7. Measure of charisma: Categories included (a) leader scales, including for example, the MLQ (Avolio et al 1995), the CKS (Conger \& Kanungo 1998), TLI (Podsakoff et al 1990), or the CLIO (De Hoogh et al 2004), coded independently, (b) measures coded from characteristics of the leader, (c) measures coded from his verbal rhetoric and non-verbal behaviors, (d) direct measures (e.g., is he/she charismatic?) and (e) other measures. Note, we excluded coding features from articles that manipulated charisma in an experiment, even if they performed a manipulation check using a measure of charisma (see Table 8).

[Table 8 here] 
$\underline{\text { 8. Endogenous charisma used as regressor: Here we report on the type of measures (MLQ }}$ vs. others) used in studies included in our review versus the studies rejected because charisma was endogenous (see Table 9).

[Table 9 here]

9. Location: This category refers to the region in which the sample was located. Because no distinctive trends would be visible if we presented the data at the country level, we regrouped the sample locations by regions, including (a) North-America; (b) Europe; (c) Asia; (d) others; (e) cross-National; and (f) not specified (see Table 10).

[Table 10 here]

10. Qualitative articles: When an article was coded as a qualitative piece, we coded for its design and the location of the leader under study. Only percentages are reported for the latter (see Tables $11 \& 12)$.

[Tables $11 \& 12$ here]

For the correlation matrix of the key variables in coded papers, refer to Table 13.

[Table 13 here]

\section{Co-citation analyses}

We conducted co-citation analyses at the author, document, and source units of analysis.

Document co-citation analysis: We examined how many times any given pair of documents (i.e., articles, chapters, or books) have been cited by the 280 articles included in this review. This analysis can help us understand the intellectual base from which these 280 studies build on. As will be clear from below, we found that these studies have drawn from a single unified body of knowledge rather than from multiple unconnected bodies of knowledge. 
Using the Sci2 (2009) tool, we extracted a total of 11,364 unique references (nodes) from the 280 articles included in the review ${ }^{2}$. The largest connected component is 11,311 nodes large indicating that the intellectual landscape of charisma we see from these documents is a highly cohesive one. From this initial citation network, we further extracted a network of 661,660 cocitations (edges). For visualization purposes, we kept edges only greater than one (i.e., we excluded pairs of documents that were only cited together once in our initial set of 280 articles) and we deleted isolates. The resulting network consists of 1,615 documents and 28,619 cocitations (Figure 1A). An interactive version of this network can be accessed online at the following address: http://www.hec.unil.ch/jantonakis/annualreviews/index.html. Figure 1B shows the same network keeping only the top $0.5 \%$ largest edges (i.e., edges greater than 17).

[Figures $1 \mathrm{~A}$ and 1B here]

Author co-citation analysis: Using VOSViewer (Van Eck \& Waltman 2010), we mapped the author co-citation network of our sample of empirical studies of charisma. Note that this network is based only on first authors. From 7,193 first authors, we retained the top 50 authors (i.e., authors who have been cited at least 28 times). The resulting network can be seen in the main paper (Figure 1B).

Source co-citation analysis: Additionally, we thought to understand the network of sources (i.e., journals, books, etc.) cited by empirical studies of charisma. Again, using VOSViewer, we mapped the source co-citation network of our full sample of empirical studies of charisma. From the resulting 5,856 sources, we retained all sources which had been cited at least

\footnotetext{
${ }^{2}$ We preprocessed the data by running the built-it detect duplicate algorithm. Note, typographical errors aside, a given work may still referenced in multiple ways. This issue is particularly important with regard to Weber's work, which is at times referenced to in the original German version or in an English translation, as part of collected works, or as other works about Weber. As a result of this issue, and because this analysis is at the document level, the influence of Weber's work is somewhat diluted (e.g., in Figure 1). In other words, what we graphically show is a lower bound estimate of the influence of Weber's work. In fact, among the 280 papers we analyzed we found that Weber's work was the most frequently cited (i.e., 73.94\% cited Weber's work; however, $55.71 \%$ cited Bass, $54.64 \%$ cited House, $50.71 \%$ cited Conger, and $45.71 \%$ cited Shamir).
} 
28 times $(n=62)$. The resulting map can be seen in Figure 2. This figure nicely shows the contribution of (a) sociology and political science (blue nodes), (b) applied psychology (green nodes), and (c) management (red nodes) to the study of charisma.

[Figure 2 here] 
Table 1: Predicting Citations by Article Type

\begin{tabular}{|c|c|c|c|c|c|c|c|c|c|c|}
\hline (Model) & $(1)$ & $(2)$ & (3) & (4) & $(5)$ & $(6)$ & $(7)$ & $(8)$ & $(9)$ & $(10)$ \\
\hline \multirow[t]{2}{*}{ Article age } & $.23 * *$ & $.20 * *$ & $.20 * *$ & $.20 * *$ & $.22 * *$ & $.15^{* *}$ & $.13 * *$ & $.11 * *$ & $.10 * *$ & $.10^{* *}$ \\
\hline & $(5.67)$ & $(5.17)$ & $(5.45)$ & $(5.78)$ & $(7.52)$ & $(4.42)$ & $(4.10)$ & $(3.46)$ & $(4.65)$ & $(4.65)$ \\
\hline \multirow[t]{2}{*}{ Article age $^{2}$} & $-.00 * *$ & $-.00 * *$ & $-.00 * *$ & $-.00 * *$ & $-.00 * *$ & $-.00 * *$ & $-.00 * *$ & $-.00 * *$ & $-.00 * *$ & $-.00 * *$ \\
\hline & $(4.10)$ & $(3.79)$ & $(4.09)$ & $(4.52)$ & $(5.89)$ & $(3.52)$ & $(3.40)$ & $(2.78)$ & $(3.82)$ & $(3.82)$ \\
\hline \multirow[t]{2}{*}{ Cited Refs } & $.02 * *$ & $.01 * *$ & $.01 * *$ & $.01 * *$ & $.01 * *$ & $.01 * *$ & $.01 * *$ & $.01 * *$ & $.01 * *$ & $.01 * *$ \\
\hline & (7.87) & $(10.87)$ & $(6.28)$ & $(4.16)$ & $(4.50)$ & $(7.13)$ & $(9.59)$ & $(8.51)$ & $(7.43)$ & $(7.43)$ \\
\hline \multirow[t]{2}{*}{ \# of Authors } & $.44^{*}$ & .30 & .24 & $.18^{*}$ & $.19 * *$ & $.35^{*}$ & $.27 *$ & .21 & $.16+$ & $.16+$ \\
\hline & $(2.34)$ & $(1.95)$ & $(1.67)$ & $(2.34)$ & $(2.60)$ & $(2.29)$ & $(1.96)$ & $(1.61)$ & (1.96) & $(1.96)$ \\
\hline \multirow[t]{2}{*}{ Quantitative } & & $.93 * *$ & $.60 * *$ & $.36^{*}$ & $.33^{*}$ & & $.78 * *$ & $.54 * *$ & $.32 * *$ & $.32 * *$ \\
\hline & & $(6.48)$ & $(3.31)$ & $(2.09)$ & $(1.97)$ & & $(6.50)$ & $(4.54)$ & $(3.20)$ & $(3.20)$ \\
\hline \multirow[t]{2}{*}{ Review } & & $.99 * *$ & .56 & $.71 * *$ & $.71 * *$ & & $1.00 * *$ & $.70 * *$ & $.77 * *$ & $.77 * *$ \\
\hline & & $(3.32)$ & $(1.75)$ & $(2.66)$ & $(2.61)$ & & $(3.85)$ & $(2.89)$ & $(3.64)$ & $(3.64)$ \\
\hline \multirow[t]{2}{*}{ Theory } & & $1.00^{* * *}$ & $.70 * *$ & $.34 *$ & $.32 *$ & & $1.03 * *$ & $.77 * *$ & $.38 * *$ & $.38 * *$ \\
\hline & & $(4.45)$ & $(3.27)$ & $(2.17)$ & $(2.09)$ & & $(4.25)$ & $(3.42)$ & $(3.60)$ & $(3.60)$ \\
\hline \multirow[t]{2}{*}{ Agg. impact factor field } & & & $1.31 * *$ & $.67 *$ & $.64^{*}$ & & & $1.16^{* *}$ & $.65^{*}$ & $.65^{*}$ \\
\hline & & & $(3.09)$ & $(2.38)$ & $(2.25)$ & & & $(2.79)$ & $(2.30)$ & $(2.30)$ \\
\hline \multirow[t]{2}{*}{ Author ave. affilliation rank ${ }^{\mathrm{a}}$} & & & $.00 * *$ & $.00^{*}$ & $.00 *$ & & & $.00 * *$ & $.00 * *$ & $.00 * *$ \\
\hline & & & $(4.54)$ & $(2.48)$ & $(2.29)$ & & & $(4.23)$ & $(2.63)$ & $(2.63)$ \\
\hline \multirow[t]{2}{*}{ Impact factor journal } & & & & $.30 * *$ & $.31 * *$ & & & & $.24 * *$ & $.24 * *$ \\
\hline & & & & $(4.25)$ & $(4.08)$ & & & & $(4.69)$ & $(4.69)$ \\
\hline \multirow[t]{2}{*}{ Constant } & $-.98 *$ & $-1.17 * *$ & $-2.84 * *$ & $-2.07 * *$ & $-2.31 * *$ & $-2.04 * *$ & $-2.27 * *$ & $-3.74 * *$ & $-3.13 * *$ & $-3.13 * *$ \\
\hline & $(2.24)$ & $(3.48)$ & $(6.49)$ & $(4.73)$ & $(5.63)$ & $(3.72)$ & $(4.86)$ & $(8.64)$ & $(8.69)$ & $(8.68)$ \\
\hline Pseudo-R square $^{\text {b }}$ & $.49 * *$ & $.54 * *$ & $.59 * *$ & $.69 * *$ & $.67 * *$ & $.37 * *$ & $.43^{* *}$ & $.50 * *$ & $.59 * *$ & $.59 * *$ \\
\hline
\end{tabular}

Omitted category for article type is "Qualitative" Model 1-4: predicting times cited using zero-inflated negative binomial regression; Model 5 predicting times cited using negative binomial regression; Model 6-9: predicting times cited per year using zero-inflated negative binomial regression; Model 10 predicting times cited per year using negative binomial regression; $\mathrm{n}=280$ (models 1-3, 6-8); $\mathrm{n}=276$ (models 4, 5, 9, and 10) - the reduced n-size is because some journals do not have an impact factor. ${ }^{a}$ Reverse coded thus a higher number indicates higher rank; ${ }^{b} \mathrm{~W} a l d$ test for change in $\mathrm{r}$-square from additional regressors from previous model (for Models 1, 5, 6, and 10 it is the Wald test for the $\mathrm{r}$-square for the full equation); pseudo R-square is based on the Cox-Snell (1989) method. The inflation coefficient is significant for final models (i.e., 4 and 8 ) as is the dispersion parameter (i.e., $\ln (\alpha)$ for models $4,5,9$, and 10 ). $12.50 \%$ of articles were not cited. Cluster robust z-statistics in parentheses (using unique journal categories and category combinations as per the Web of Science journal impact factor listings); ** $\mathrm{p}<.01, * \mathrm{p}<.05,+\mathrm{p}=.05$. 
Table 2: Trend for conceptualization of charisma

\begin{tabular}{|c|c|c|c|c|c|c|c|c|c|c|c|c|c|c|c|c|c|c|c|c|c|c|c|c|c|c|}
\hline Year & & $\stackrel{+}{\sigma}$ & Бొ & $\begin{array}{l}\text { t̊ } \\
\stackrel{2}{ }\end{array}$ & $\begin{array}{l}n \\
2\end{array}$ & $\begin{array}{l}\circ \\
\stackrel{\circ}{2}\end{array}$ & $\stackrel{\widehat{\circ}}{2}$ & $\begin{array}{l}\infty \\
\stackrel{0}{2}\end{array}$ & ڤે & 合 & $\stackrel{N}{\Omega}$ & $\stackrel{\mathfrak{n}}{\Omega}$ & $\stackrel{+}{\stackrel{\Delta}{\Omega}}$ & $\stackrel{n}{\stackrel{2}{2}}$ & $\begin{array}{l}0 \\
\stackrel{2}{2}\end{array}$ & $\stackrel{\infty}{\stackrel{2}{2}}$ & 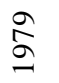 & $\begin{array}{l}\stackrel{\infty}{2} \\
\stackrel{-}{9}\end{array}$ & $\begin{array}{l}\stackrel{ }{\infty} \\
\stackrel{\infty}{\varrho}\end{array}$ & $\begin{array}{l}\mathscr{\infty} \\
\stackrel{\infty}{\Omega}\end{array}$ & $\begin{array}{l}\mathscr{n} \\
\stackrel{\infty}{\Omega}\end{array}$ & 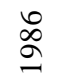 & $\stackrel{\infty}{\infty}$ & $\begin{array}{l}\infty \\
\stackrel{\infty}{\varrho} \\
\stackrel{2}{2}\end{array}$ & $\stackrel{\stackrel{\infty}{\varrho}}{\stackrel{2}{2}}$ & ஓ \\
\hline Perception / Attribution & & 0 & 0 & 2 & 3 & 0 & 0 & 1 & 0 & 1 & 0 & 0 & 1 & 2 & 0 & 1 & 1 & 1 & 0 & 0 & 0 & 0 & 2 & 0 & 0 & 0 \\
\hline Personality traits & & 0 & 1 & 0 & 0 & 0 & 1 & 3 & 0 & 0 & 0 & 0 & 2 & 1 & 0 & 1 & 0 & 3 & 0 & 1 & 1 & 0 & 0 & 1 & 0 & 0 \\
\hline Behavior & & 0 & 0 & 0 & 0 & 0 & 0 & 0 & 0 & 0 & 0 & 0 & 0 & 0 & 0 & 0 & 0 & 0 & 0 & 0 & 0 & 0 & 1 & 0 & 0 & 1 \\
\hline Relationship & & 1 & 0 & 0 & 0 & 1 & 1 & 0 & 1 & 0 & 2 & 1 & 0 & 1 & 1 & 3 & 0 & 0 & 2 & 0 & 1 & 1 & 0 & 1 & 3 & 0 \\
\hline Attitude & & 0 & 0 & 0 & 0 & 0 & 0 & 0 & 0 & 0 & 0 & 0 & 0 & 0 & 0 & 0 & 0 & 0 & 0 & 0 & 0 & 0 & 0 & 0 & 0 & 0 \\
\hline \multirow[t]{2}{*}{ Total } & & 1 & 1 & 2 & 3 & 1 & 2 & 4 & 1 & 1 & 2 & 1 & 3 & 4 & 1 & 5 & 1 & 4 & 2 & 1 & 2 & 1 & 3 & 2 & 3 & 1 \\
\hline & à & ๙ & $\stackrel{\check{\alpha}}{2}$ & $\stackrel{\curvearrowleft}{2}$ & ڤั & $\hat{\Omega}$ & $\stackrel{\infty}{\stackrel{\circ}{二}}$ & $\stackrel{\text { ลे }}{2}$ & ஓ & 홍 & 용 & ֻ̊̊̊ & $\underset{\overbrace{}}{\stackrel{\overbrace{}}{~}}$ & ஜ̊ & ঃ & 용 & $\stackrel{\infty}{\stackrel{ᄋ}{ٍ ~}}$ & ஓి & $\stackrel{\circ}{\stackrel{2}{\circ}}$ & $\overline{\bar{D}}$ & $\stackrel{\sim}{\stackrel{N}{\sigma}}$ & $\stackrel{m}{\stackrel{n}{N}}$ & 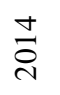 & & $\stackrel{\overrightarrow{0}}{0}$ & 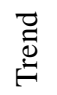 \\
\hline Perception / Attribution & 2 & 2 & 0 & 2 & 2 & 3 & 4 & 7 & 1 & 0 & 2 & 2 & 6 & 4 & 3 & 4 & 7 & 6 & 7 & 4 & 6 & 3 & 6 & & 98 & ++ \\
\hline Personality traits & 0 & 1 & 1 & 0 & 0 & 3 & 3 & 1 & 4 & 3 & 1 & 1 & 2 & 3 & 2 & 5 & 6 & 4 & 4 & 1 & 2 & 4 & 4 & & 70 & ++ \\
\hline Behavior & 0 & 1 & 1 & 0 & 1 & 0 & 2 & 4 & 2 & 5 & 1 & 2 & 1 & 2 & 3 & 1 & 3 & 3 & 2 & 6 & 3 & 6 & 7 & & 58 & ++ \\
\hline Relationship & 2 & 0 & 0 & 1 & 0 & 2 & 0 & 3 & 2 & 1 & 2 & 0 & 1 & 1 & 2 & 1 & 1 & 3 & 2 & 2 & 3 & 1 & 0 & & 50 & + \\
\hline Attitude & 0 & 1 & 0 & 0 & 0 & 0 & 0 & 0 & 0 & 1 & 0 & 0 & 0 & 0 & 0 & 0 & 0 & 0 & 0 & 1 & 0 & 0 & 1 & & 4 & \\
\hline Total & 4 & 5 & 2 & 3 & 3 & 8 & 9 & 15 & 9 & 10 & 6 & 5 & 10 & 10 & 10 & 11 & 17 & 16 & 15 & 14 & 14 & 14 & 18 & & 280 & \\
\hline
\end{tabular}


Table 3: Trend for type of article

\begin{tabular}{|c|c|c|c|c|c|c|c|c|c|c|c|c|c|c|c|c|c|c|c|c|c|c|c|c|c|c|}
\hline Year & & $\stackrel{\Delta}{2}$ & ఫొ & $\begin{array}{l}\text { ఫ̊ } \\
\stackrel{-}{\circ}\end{array}$ & $\stackrel{2}{\circ}$ & $\stackrel{8}{\circ}$ & $\hat{\sigma}$ & $\begin{array}{l}\infty \\
\stackrel{0}{2}\end{array}$ & ڤे & $\vec{a}$ & $\stackrel{N}{\hat{a}}$ & $\hat{\Omega}$ & $\underset{⿱ 亠 乂}{\stackrel{\Delta}{二}}$ & $\stackrel{n}{\stackrel{2}{2}}$ & $\stackrel{0}{\stackrel{2}{2}}$ & $\stackrel{\infty}{\stackrel{\infty}{a}}$ & $\stackrel{\hat{\Omega}}{\hat{\Omega}}$ & $\stackrel{\circ}{\stackrel{\infty}{2}}$ & 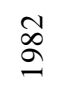 & $\stackrel{\infty}{\varrho}$ & $\stackrel{\curvearrowleft}{\infty}$ & $\begin{array}{l}\stackrel{2}{2} \\
\stackrel{2}{2}\end{array}$ & $\stackrel{\curvearrowright}{\curvearrowright}$ & $\begin{array}{l}\infty \\
\stackrel{\infty}{\Omega}\end{array}$ & $\stackrel{\infty}{2}$ & $\stackrel{2}{2}$ \\
\hline Quantitative & & 1 & 0 & 0 & 0 & 0 & 0 & 0 & 0 & 0 & 0 & 0 & 1 & 0 & 0 & 1 & 0 & 0 & 0 & 0 & 0 & 0 & 0 & 0 & 1 & 0 \\
\hline Qualitative & & 0 & 0 & 1 & 1 & 1 & 2 & 2 & 0 & 1 & 1 & 0 & 0 & 1 & 1 & 1 & 1 & 3 & 2 & 0 & 1 & 0 & 1 & 1 & 1 & 0 \\
\hline Theory & & 0 & 1 & 1 & 2 & 0 & 0 & 2 & 1 & 0 & 1 & 1 & 2 & 3 & 0 & 3 & 0 & 1 & 0 & 1 & 1 & 1 & 2 & 1 & 1 & 1 \\
\hline Review & & 0 & 0 & 0 & 0 & 0 & 0 & 0 & 0 & 0 & 0 & 0 & 0 & 0 & 0 & 0 & 0 & 0 & 0 & 0 & 0 & 0 & 0 & 0 & 0 & 0 \\
\hline \multirow[t]{2}{*}{ Total } & & 1 & 1 & 2 & 3 & 1 & 2 & 4 & 1 & 1 & 2 & 1 & 3 & 4 & 1 & 5 & 1 & 4 & 2 & 1 & 2 & 1 & 3 & 2 & 3 & 1 \\
\hline & $\bar{\sigma}$ & $\stackrel{\sigma}{\sigma}$ & $\stackrel{\Omega}{\sigma}$ & 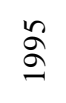 & $\stackrel{\circ}{\circ}$ & $\hat{\sigma}$ & $\stackrel{\infty}{\curvearrowright}$ & बे & ¿্ণ & $\overrightarrow{\stackrel{\leftrightarrow}{े}}$ & ڤ్రి & ڤ్̊ㅎ & ఫ্ণ & $\stackrel{\text { ڤे }}{\tilde{i}}$ & \&્ণ & 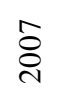 & $\stackrel{\infty}{\stackrel{i}{0}}$ & ڤे & $\stackrel{ }{\stackrel{i}{(}}$ & $\overline{\vec{i}}$ & $\stackrel{\sim}{\stackrel{i}{d}}$ & $\stackrel{m}{\stackrel{n}{i}}$ & $\underset{d}{\stackrel{d}{d}}$ & & $\stackrel{\bar{J}}{0}$ & 节 \\
\hline Quantitative & 1 & 2 & 0 & 1 & 3 & 5 & 3 & 8 & 1 & 5 & 2 & 3 & 9 & 6 & 4 & 4 & 8 & 6 & 6 & 11 & 5 & 6 & 9 & & 112 & ++ \\
\hline Qualitative & 1 & 1 & 0 & 0 & 0 & 1 & 1 & 3 & 5 & 4 & 3 & 1 & 0 & 3 & 2 & 6 & 5 & 7 & 5 & 3 & 4 & 6 & 7 & & 90 & ++ \\
\hline Theory & 2 & 2 & 2 & 2 & 0 & 2 & 5 & 3 & 3 & 0 & 1 & 1 & 1 & 1 & 2 & 1 & 4 & 1 & 4 & 0 & 3 & 2 & 1 & & 69 & \\
\hline Review & 0 & 0 & 0 & 0 & 0 & 0 & 0 & 1 & 0 & 1 & 0 & 0 & 0 & 0 & 2 & 0 & 0 & 2 & 0 & 0 & 2 & 0 & 1 & & 9 & ++ \\
\hline Total & 4 & 5 & 2 & 3 & 3 & 8 & 9 & 15 & 9 & 10 & 6 & 5 & 10 & 10 & 10 & 11 & 17 & 16 & 15 & 14 & 14 & 14 & 18 & & 280 & \\
\hline
\end{tabular}


Table 4: Trend for sample occupation

\begin{tabular}{|c|c|c|c|c|c|c|c|c|c|c|c|c|c|c|c|c|c|c|c|c|c|c|c|c|c|c|c|c|}
\hline Year & $\stackrel{+}{\stackrel{2}{\varrho}}$ & 志 & $\stackrel{\infty}{\stackrel{\infty}{\vdots}}$ & $\stackrel{\circ}{\circ}$ & $\bar{\partial}$ & ๙ิ & $\stackrel{2}{2}$ & ஃั & $\hat{a}$ & $\begin{array}{l}\infty \\
\stackrel{2}{\sigma}\end{array}$ & 亏े & ¿্ণ & $\overrightarrow{\mathrm{d}}$ & 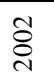 & ڤి & ఫ̊ & 苂 & ¿̊̊ & $\hat{\mathrm{o}}$ & $\stackrel{\infty}{0}$ & ठे & $\stackrel{\circ}{\circ}$ & $\overrightarrow{\text { ¿े }}$ & $\stackrel{\sim}{\stackrel{\sim}{a}}$ & $\stackrel{m}{\vec{i}}$ & $\underset{\sim}{\Delta}$ & जٓ & $\begin{array}{l}\vec{Z} \\
\vec{D}\end{array}$ \\
\hline Private \& Public companies & 0 & 0 & 0 & 0 & 0 & 0 & 0 & 1 & 0 & 1 & 1 & 1 & 0 & 0 & 2 & 2 & 3 & 1 & 2 & 3 & 2 & 1 & 6 & 1 & 1 & 3 & 31 & + \\
\hline Undergraduate students & 0 & 0 & 0 & 1 & 0 & 1 & 1 & 2 & 3 & 0 & 3 & 0 & 3 & 1 & 3 & 7 & 3 & 2 & 3 & 7 & 3 & 3 & 1 & 2 & 3 & 4 & 56 & + \\
\hline Graduate \& EMBA students & 0 & 0 & 0 & 0 & 0 & 1 & 0 & 0 & 0 & 0 & 2 & 0 & 0 & 0 & 1 & 2 & 1 & 1 & 0 & 0 & 1 & 0 & 1 & 2 & 0 & 1 & 13 & \\
\hline Politicians & 0 & 1 & 0 & 0 & 1 & 0 & 0 & 0 & 2 & 1 & 1 & 0 & 4 & 0 & 0 & 4 & 2 & 1 & 0 & 1 & 1 & 0 & 1 & 2 & 2 & 1 & 25 & \\
\hline Others & 1 & 0 & 1 & 0 & 0 & 1 & 0 & 0 & 0 & 1 & 1 & 0 & 0 & 2 & 0 & 0 & 0 & 0 & 0 & 1 & 0 & 3 & 4 & 0 & 1 & 1 & 17 & \\
\hline Total & 1 & 1 & 1 & 1 & 1 & 3 & 1 & 3 & 5 & 3 & 8 & 1 & 7 & 3 & 6 & 15 & 9 & 5 & 5 & 12 & 7 & 7 & 13 & 7 & 7 & 10 & 142 & \\
\hline
\end{tabular}


Table 5: Trend for type of design

\begin{tabular}{|c|c|c|c|c|c|c|c|c|c|c|c|c|c|c|c|c|c|c|c|c|c|c|c|c|c|c|c|c|}
\hline Year & $\stackrel{+}{\aleph}$ & $\stackrel{+}{\stackrel{+}{\Omega}}$ & $\stackrel{\infty}{\stackrel{\infty}{2}}$ & $\stackrel{\circ}{\stackrel{\infty}{\sigma}}$ & $\bar{\Xi}$ & $\widehat{\Omega}$ & $\stackrel{2}{2}$ & ঃ & $\hat{\mathrm{a}}$ & $\stackrel{\infty}{\circ}$ & Әे & $\stackrel{\text { ¿े }}{8}$ & $\overrightarrow{\grave{O}}$ & ڤ్రి & ڤ̊̀ & 总 & 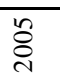 & 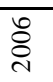 & $\hat{\stackrel{N}{0}}$ & $\begin{array}{l}\infty \\
\stackrel{\text { ¿े }}{ }\end{array}$ & ठे & $\stackrel{\circ}{\stackrel{\sim}{\circ}}$ & $\vec{\Xi}$ & 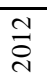 & $\stackrel{m}{\grave{N}}$ & $\underset{\sim}{\vec{\sim}}$ & 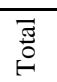 & \begin{tabular}{l}
$\vec{Z}$ \\
$\vec{D}$ \\
\multirow{E}{*}{}
\end{tabular} \\
\hline Experiments & 0 & 0 & 0 & 1 & 0 & 1 & 0 & 2 & 2 & 0 & 6 & 0 & 3 & 0 & 5 & 5 & 1 & 2 & 2 & 6 & 2 & 3 & 3 & 2 & 2 & 3 & 51 & + \\
\hline Field Study & 1 & 0 & 1 & 0 & 0 & 1 & 0 & 1 & 1 & 2 & 1 & 1 & 1 & 2 & 0 & 3 & 5 & 3 & 3 & 3 & 2 & 3 & 6 & 2 & 3 & 4 & 49 & ++ \\
\hline Archival Data & 0 & 1 & 0 & 0 & 1 & 0 & 0 & 0 & 2 & 1 & 1 & 0 & 3 & 1 & 0 & 5 & 2 & 0 & 0 & 2 & 2 & 1 & 4 & 2 & 2 & 1 & 31 & \\
\hline Interview & 0 & 1 & 0 & 0 & 0 & 0 & 1 & 0 & 0 & 0 & 0 & 0 & 0 & 0 & 0 & 0 & 1 & 0 & 0 & 0 & 0 & 0 & 0 & 0 & 0 & 2 & 5 & \\
\hline Total & 1 & 2 & 1 & 1 & 1 & 2 & 1 & 3 & 5 & 3 & 8 & 1 & 7 & 3 & 5 & 13 & 9 & 5 & 5 & 11 & 6 & 7 & 13 & 6 & 7 & 10 & 136 & \\
\hline
\end{tabular}


Table 6: Trend for type of variable

\begin{tabular}{|c|c|c|c|c|c|c|c|c|c|c|c|c|c|c|c|c|c|c|c|c|c|c|c|c|c|c|c|c|}
\hline Year & $\stackrel{+}{\stackrel{\Delta}{2}}$ & 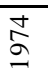 & $\stackrel{\infty}{\stackrel{\infty}{2}}$ & $\begin{array}{l}\stackrel{\circ}{2} \\
\stackrel{2}{2}\end{array}$ & $\bar{\sigma}$ & $\widetilde{\Omega}$ & $\begin{array}{l}\check{2} \\
\stackrel{2}{2}\end{array}$ & $\stackrel{\circ}{\circ}$ & à & $\begin{array}{l}\infty \\
\stackrel{2}{2}\end{array}$ & $\stackrel{\partial}{\partial}$ & 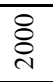 & $\overrightarrow{\grave{O}}$ & ठิ & 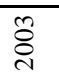 & $\begin{array}{l}\text { ț } \\
\text { Oे }\end{array}$ & 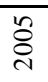 & $\begin{array}{l} \\
\stackrel{্}{\Lambda}\end{array}$ & $\hat{\stackrel{\leftrightarrow}{0}}$ & $\begin{array}{l}\infty \\
\stackrel{\leftrightarrow}{0}\end{array}$ & ڤे̀े & $\stackrel{\circ}{\stackrel{2}{2}}$ & $\overline{\vec{i}}$ & $\stackrel{\sim}{\stackrel{\sim}{*}}$ & $\stackrel{m}{a}$ & $\underset{⿱}{\vec{d}}$ & స్ & $\begin{array}{l}\bar{\nabla} \\
\vec{D} \\
\vec{E}\end{array}$ \\
\hline Dependent Variable & 0 & 1 & 1 & 0 & 1 & 1 & 0 & 2 & 4 & 3 & 3 & 1 & 3 & 3 & 5 & 8 & 8 & 4 & 5 & 5 & 4 & 5 & 9 & 5 & 4 & 6 & 91 & ++ \\
\hline Independent Variable & 1 & 0 & 0 & 1 & 0 & 1 & 1 & 1 & 1 & 0 & 5 & 0 & 4 & 0 & 0 & 5 & 0 & 1 & 1 & 6 & 2 & 2 & 5 & 0 & 3 & 3 & 43 & \\
\hline Mediator & 0 & 0 & 0 & 0 & 0 & 0 & 0 & 0 & 0 & 0 & 0 & 0 & 0 & 0 & 0 & 0 & 0 & 0 & 0 & 0 & 0 & 0 & 1 & 0 & 0 & 0 & 1 & \\
\hline Moderator & 0 & 0 & 0 & 0 & 0 & 1 & 0 & 0 & 0 & 0 & 0 & 0 & 0 & 0 & 0 & 0 & 0 & 0 & 0 & 0 & 0 & 0 & 0 & 1 & 0 & 0 & 2 & \\
\hline Total & 1 & 1 & 1 & 1 & 1 & 3 & 1 & 3 & 5 & 3 & 8 & 1 & 7 & 3 & 5 & 13 & 8 & 5 & 6 & 11 & 6 & 7 & 15 & 6 & 7 & 9 & 137 & \\
\hline
\end{tabular}


Table 7: Trend for type of leader

\begin{tabular}{|c|c|c|c|c|c|c|c|c|c|c|c|c|c|c|c|c|c|c|c|c|c|c|c|c|c|c|c|c|}
\hline Year & 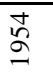 & 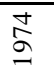 & $\stackrel{\infty}{\stackrel{\infty}{\varrho}}$ & $\begin{array}{l}\stackrel{\circ}{\circ} \\
\stackrel{2}{a}\end{array}$ & $\bar{\partial}$ & مू & $\begin{array}{l}\stackrel{2}{\circ} \\
\stackrel{2}{2}\end{array}$ & $\stackrel{2}{\circ}$ & $\hat{\mathrm{a}}$ & $\begin{array}{l}\text { 吕 } \\
\stackrel{2}{2}\end{array}$ & Әे & \&્ণ & $\overline{\grave{O}}$ & ণิ & ڤ્ণ & ర্ণ & $\stackrel{\text { ڤે }}{0}$ & ¿্র & ڤ్) & $\begin{array}{l}\infty \\
\stackrel{0}{0}\end{array}$ & 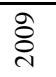 & 을 & $\vec{\Xi}$ & $\stackrel{\widetilde{N}}{\stackrel{2}{2}}$ & $\stackrel{m}{\stackrel{m}{i}}$ & $\underset{⿱ 亠}{\stackrel{\Delta}{*}}$ & 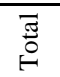 & $\begin{array}{l}\overline{\vec{D}} \\
\vec{D}\end{array}$ \\
\hline Real Leader I & 0 & 0 & 1 & 0 & 0 & 1 & 1 & 2 & 2 & 2 & 1 & 1 & 3 & 2 & 4 & 3 & 4 & 3 & 3 & 4 & 4 & 2 & 8 & 1 & 2 & 4 & 58 & + \\
\hline Real Leader II & 1 & 1 & 0 & 0 & 1 & 0 & 0 & 0 & 3 & 1 & 2 & 0 & 4 & 1 & 0 & 7 & 3 & 0 & 2 & 2 & 2 & 1 & 4 & 3 & 4 & 3 & 45 & ++ \\
\hline Hypothetical Leader & 0 & 0 & 0 & 0 & 0 & 1 & 0 & 0 & 0 & 0 & 1 & 0 & 0 & 0 & 1 & 3 & 1 & 2 & 0 & 4 & 0 & 4 & 0 & 0 & 0 & 1 & 18 & \\
\hline Actor & 0 & 0 & 0 & 1 & 0 & 0 & 0 & 1 & 0 & 0 & 4 & 0 & 0 & 0 & 0 & 0 & 0 & 0 & 0 & 1 & 0 & 0 & 1 & 2 & 1 & 2 & 13 & \\
\hline Total & 1 & 1 & 1 & 1 & 1 & 2 & 1 & 3 & 5 & 3 & 8 & 1 & 7 & 3 & 5 & 13 & 8 & 5 & 5 & 11 & 6 & 7 & 13 & 6 & 7 & 10 & 134 & \\
\hline
\end{tabular}


Table 8: Trend for measure of charisma

\begin{tabular}{|c|c|c|c|c|c|c|c|c|c|c|c|c|c|c|c|c|c|c|c|c|c|c|c|c|c|c|c|}
\hline Year & $\stackrel{\sharp}{\approx}$ & 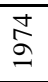 & \begin{tabular}{l}
$\infty$ \\
\multirow{2}{\sigma}{}
\end{tabular} & $\bar{\sigma}$ & $\stackrel{\text { }}{\sigma}$ & $\stackrel{2}{2}$ & $\begin{array}{l}\circ \\
\stackrel{2}{2}\end{array}$ & $\hat{\sigma}$ & $\stackrel{\infty}{\circ}$ & $\stackrel{\partial}{\sigma}$ & 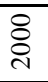 & $\overline{\mathrm{\sigma}}$ & 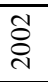 & $\hat{\tilde{\sigma}}$ & $\begin{array}{l}\overrightarrow{0} \\
\text { d }\end{array}$ & 客 & 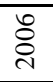 & $\widehat{\grave{d}}$ & 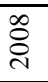 & ڤ્ণ & 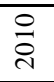 & $\overline{\vec{i}}$ & $\underset{\sim}{\stackrel{N}{\sim}}$ & $\stackrel{m}{\stackrel{n}{d}}$ & $\underset{i}{\vec{d}}$ & 㞼 & $\begin{array}{l}\overrightarrow{\vec{E}} \\
\overrightarrow{0} \\
\vec{E}\end{array}$ \\
\hline MLQ & 0 & 0 & 0 & 0 & 0 & 0 & 2 & 2 & 1 & 1 & 0 & 0 & 2 & 1 & 2 & 1 & 3 & 4 & 1 & 2 & 2 & 4 & 1 & 3 & 4 & 36 & ++ \\
\hline Others & 0 & 1 & 1 & 0 & 2 & 0 & 0 & 1 & 0 & 4 & 0 & 1 & 0 & 0 & 1 & 3 & 1 & 1 & 3 & 1 & 1 & 0 & 2 & 3 & 2 & 28 & ++ \\
\hline Coded from verbal $\&$ non-verbal & 0 & 0 & 0 & 1 & 0 & 0 & 0 & 0 & 0 & 0 & 0 & 3 & 1 & 3 & 4 & 2 & 0 & 0 & 2 & 2 & 1 & 2 & 2 & 0 & 0 & 23 & \\
\hline Coded from characteristics of leader & 0 & 0 & 0 & 1 & 0 & 0 & 0 & 2 & 1 & 1 & 0 & 3 & 0 & 0 & 2 & 0 & 0 & 0 & 1 & 1 & 0 & 2 & 1 & 2 & 1 & 18 & \\
\hline Direct measure & 1 & 0 & 0 & 0 & 0 & 1 & 0 & 0 & 1 & 0 & 0 & 0 & 0 & 0 & 1 & 1 & 1 & 2 & 0 & 0 & 0 & 2 & 0 & 0 & 1 & 11 & \\
\hline CKS & 0 & 0 & 0 & 0 & 0 & 0 & 0 & 0 & 0 & 0 & 1 & 0 & 0 & 1 & 3 & 1 & 0 & 0 & 0 & 0 & 2 & 0 & 0 & 0 & 1 & 9 & \\
\hline TLI & 0 & 0 & 0 & 0 & 0 & 0 & 0 & 0 & 0 & 0 & 0 & 0 & 0 & 0 & 0 & 0 & 0 & 0 & 1 & 0 & 0 & 2 & 0 & 0 & 0 & 3 & \\
\hline CLIO & 0 & 0 & 0 & 0 & 0 & 0 & 0 & 0 & 0 & 0 & 0 & 0 & 0 & 0 & 0 & 1 & 0 & 1 & 0 & 0 & 0 & 0 & 1 & 0 & 0 & 3 & \\
\hline Total & 1 & 1 & 1 & 2 & 2 & 1 & 2 & 5 & 3 & 6 & 1 & 7 & 3 & 5 & 13 & 9 & 5 & 8 & 8 & 6 & 6 & 12 & 7 & 8 & 9 & 131 & \\
\hline
\end{tabular}


Table 9: Trend for use of MLQ and other measures

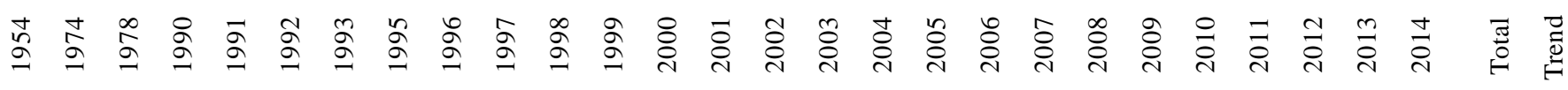

\begin{tabular}{|c|c|c|c|c|c|c|c|c|c|c|c|c|c|c|c|c|c|c|c|c|c|c|c|c|c|c|c|c|c|}
\hline MLQ Excluded & 0 & 0 & 0 & 1 & 0 & 1 & 1 & 1 & 0 & 0 & 1 & 1 & 0 & 2 & 4 & 2 & 3 & 2 & 3 & 6 & 3 & 5 & 5 & & & 4 & 5 & 59 & ++ \\
\hline MLQ Included & 0 & 0 & 0 & 0 & 0 & 0 & 0 & 0 & 2 & 2 & 1 & 1 & 0 & 0 & 2 & 1 & 2 & 1 & 3 & 4 & 1 & 2 & 2 & & & 3 & 4 & 36 & + \\
\hline Total MLQ & 0 & 0 & 0 & 1 & 0 & 1 & 1 & 1 & 2 & 2 & 2 & 2 & 0 & 2 & 6 & 3 & 5 & 3 & 6 & 10 & 4 & 7 & 7 & & & 7 & 9 & 95 & ++ \\
\hline Other Measures Excluded & 0 & 0 & 0 & 0 & 0 & 1 & 0 & 1 & 0 & 1 & 2 & 0 & 1 & 0 & 1 & 0 & 0 & 2 & 3 & 0 & 2 & 3 & 2 & & & 9 & 4 & 41 & ++ \\
\hline Other Measures Included & 1 & 1 & 1 & 0 & 2 & 2 & 0 & 1 & 0 & 3 & 2 & 5 & 1 & 7 & 1 & 4 & 11 & 8 & 2 & 4 & 7 & 4 & 4 & & & 5 & 5 & 95 & ++ \\
\hline Total Other Measures & 1 & 1 & 1 & 0 & 2 & 3 & 0 & 2 & 0 & 4 & 4 & 5 & 2 & 7 & 2 & 4 & 11 & 10 & 5 & 4 & 9 & 7 & 6 & 1 & & 14 & 9 & 136 & ++ \\
\hline
\end{tabular}

Total

\begin{tabular}{lllllllllllllllllllllllllllll}
1 & 1 & 1 & 1 & 2 & 4 & 1 & 3 & 2 & 6 & 6 & 7 & 2 & 9 & 8 & 7 & 16 & 13 & 11 & 14 & 13 & 14 & 13 & 23 & 14 & 21 & 18 & 231 & \\
\hline
\end{tabular}


Table 10: Trend for location of the sample

\begin{tabular}{|c|c|c|c|c|c|c|c|c|c|c|c|c|c|c|c|c|c|c|c|c|c|c|c|c|c|c|c|c|}
\hline Year & $\begin{array}{l}\stackrel{+}{\sim} \\
\stackrel{2}{二}\end{array}$ & 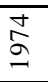 & $\stackrel{\infty}{\stackrel{\infty}{2}}$ & $\begin{array}{l}\stackrel{a}{\partial} \\
\stackrel{-}{a}\end{array}$ & $\bar{\sigma}$ & $\check{\sigma}$ & $\begin{array}{l}\check{2} \\
\stackrel{2}{2}\end{array}$ & $\begin{array}{l}\text { ஃे } \\
\stackrel{2}{ }\end{array}$ & $\hat{\mathrm{a}}$ & $\begin{array}{l}\infty \\
\stackrel{2}{\sigma}\end{array}$ & $\stackrel{\partial}{\partial}$ & 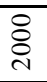 & $\overrightarrow{\stackrel{a}{0}}$ & రิ & 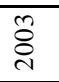 & 总 & 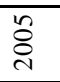 & $\begin{array}{l} \\
\stackrel{্}{\Lambda}\end{array}$ & $\hat{\stackrel{\leftrightarrow}{0}}$ & 㐫 & 仓े & $\stackrel{\circ}{\stackrel{2}{c}}$ & 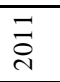 & $\stackrel{\sim}{\stackrel{\sim}{*}}$ & $\stackrel{m}{a}$ & $\underset{d}{\vec{d}}$ & 氶 & $\begin{array}{l}\overrightarrow{\vec{E}} \\
\vec{E}\end{array}$ \\
\hline North America & 1 & 0 & 1 & 1 & 1 & 1 & 0 & 2 & 4 & 2 & 6 & 1 & 6 & 1 & 2 & 6 & 3 & 1 & 3 & 4 & 5 & 3 & 6 & 3 & 4 & 3 & 70 & + \\
\hline Europe & 0 & 0 & 0 & 0 & 0 & 0 & 0 & 0 & 0 & 0 & 0 & 0 & 0 & 0 & 2 & 2 & 4 & 0 & 1 & 4 & 0 & 2 & 5 & 2 & 1 & 2 & 25 & ++ \\
\hline Not Specified & 0 & 0 & 0 & 0 & 0 & 0 & 0 & 1 & 0 & 0 & 1 & 0 & 0 & 1 & 0 & 3 & 1 & 0 & 0 & 2 & 0 & 1 & 1 & 1 & 1 & 2 & 15 & + \\
\hline Cross-National & 0 & 1 & 0 & 0 & 0 & 0 & 0 & 0 & 0 & 0 & 1 & 0 & 0 & 1 & 1 & 1 & 0 & 1 & 1 & 1 & 1 & 0 & 0 & 0 & 1 & 2 & 12 & \\
\hline Asia & 0 & 0 & 0 & 0 & 0 & 1 & 1 & 0 & 0 & 1 & 0 & 0 & 1 & 0 & 0 & 1 & 0 & 1 & 0 & 0 & 0 & 1 & 0 & 0 & 0 & 1 & 8 & \\
\hline Others & 0 & 0 & 0 & 0 & 0 & 0 & 0 & 0 & 1 & 0 & 0 & 0 & 0 & 0 & 0 & 0 & 0 & 2 & 0 & 0 & 0 & 0 & 1 & 0 & 0 & 0 & 4 & \\
\hline Total & 1 & 1 & 1 & 1 & 1 & 2 & 1 & 3 & 5 & 3 & 8 & 1 & 7 & 3 & 5 & 13 & 8 & 5 & 5 & 11 & 6 & 7 & 13 & 6 & 7 & 10 & 134 & \\
\hline
\end{tabular}


Table 11: Trend for design of qualitative studies

\begin{tabular}{|c|c|c|c|c|c|c|c|c|c|c|c|c|c|c|c|c|c|c|c|c|c|c|c|c|c|c|c|c|c|c|c|c|c|c|c|c|c|c|c|c|}
\hline Year & 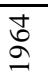 & $\stackrel{2}{2}$ & ஜ̊ & $\hat{\circ}$ & \begin{tabular}{l}
0 \\
\hdashline
\end{tabular} & $\bar{\Omega}$ & స్ & $\frac{n}{2}$ & $\stackrel{\circ}{2}$ & $\stackrel{\infty}{a}$ & $\stackrel{\Im}{a}$ & $\stackrel{0}{\circ}$ & & 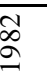 & $\begin{array}{l}\curvearrowleft \\
ٌ\end{array}$ & $\stackrel{\infty}{\circ}$ & $\begin{array}{l}\infty \\
\stackrel{\infty}{\Omega}\end{array}$ & $\begin{array}{l}\stackrel{\alpha}{\circ} \\
\stackrel{2}{a}\end{array}$ & $\bar{\Omega}$ & ๙ & $\hat{\sigma}$ & $\begin{array}{l}\infty \\
\stackrel{2}{\sigma}\end{array}$ & $\stackrel{\partial}{\Omega}$ & 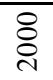 & $\overline{\mathrm{d}}$ & రิ & ڤ్రి & 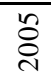 & ¿্ণ & $\hat{\tilde{\delta}}$ & $\stackrel{\infty}{\stackrel{0}{2}}$ & & 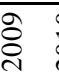 & $\stackrel{\circ}{\circ}$ & $\overline{\text { ¿ }}$ & $\stackrel{\sim}{\stackrel{\sim}{*}}$ & 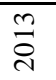 & $\stackrel{\vec{\sim}}{\stackrel{ \pm}{*}}$ & 哭 & 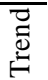 \\
\hline Case Study & 1 & 1 & 1 & 2 & 2 & 1 & 1 & 1 & 1 & 1 & 1 & & 2 & 2 & 1 & 1 & 1 & 1 & 1 & 0 & 1 & 1 & 2 & 5 & 3 & 2 & 1 & 3 & ( & & 6 & 3 & 5 & 4 & 2 & 4 & 2 & 7 & 73 & ++ \\
\hline Others & 0 & 0 & 0 & 0 & 0 & 0 & 0 & 0 & 0 & 0 & ( & & 1 & 0 & 0 & 0 & 0 & 0 & 0 & 0 & 0 & 0 & 1 & 0 & 1 & 1 & 0 & 0 & 2 & & 0 & 0 & 1 & 1 & 1 & 0 & 3 & 0 & 12 & + \\
\hline Interview & 0 & 0 & 0 & 0 & 0 & 0 & 0 & 0 & 0 & 0 & ( & & 0 & 0 & 0 & 0 & 0 & 0 & 0 & 1 & 0 & 0 & 0 & 0 & 0 & 0 & 0 & 0 & ( & c & 0 & 2 & 1 & 0 & 0 & 0 & 1 & 0 & 5 & \\
\hline Total & 1 & 1 & 1 & 2 & 2 & 1 & 1 & 1 & 1 & 1 & 1 & & 3 & 2 & 1 & 1 & 1 & 1 & 1 & 1 & 1 & 1 & 3 & 5 & 4 & 3 & 1 & 3 & 2 & & 6 & 5 & 7 & 5 & 3 & 4 & 6 & 7 & 90 & \\
\hline
\end{tabular}


Table 12: Qualitative articles location of the sample

\begin{tabular}{lcr} 
Region & Studies & Percentages \\
\hline & & \\
North America & 29 & $32.22 \%$ \\
Europe & 22 & $24.44 \%$ \\
Asia & 10 & $11.11 \%$ \\
Cross-national & 10 & $11.11 \%$ \\
Africa & 8 & $8.89 \%$ \\
South America & 7 & $7.78 \%$ \\
Not relevant & 3 & $3.33 \%$ \\
Oceania & 1 & $1.11 \%$ \\
& & \\
\hline
\end{tabular}


Table 13: Correlation matrix of key variables in coded papers

\begin{tabular}{|c|c|c|c|c|c|c|c|c|c|c|c|c|c|}
\hline & Mean & S.D. & 1 & 2 & 3 & 4 & 5 & 6 & 7 & 8 & 9 & 10 & 11 \\
\hline 1. Time cited & 31.97 & 69.84 & & & & & & & & & & & \\
\hline 2. Cites/per year & 2.37 & 3.89 & .90 & & & & & & & & & & \\
\hline 3. Years & 14.62 & 13.22 & .13 & -.05 & & & & & & & & & \\
\hline 4. Cited References & 62.95 & 36.24 & .15 & .35 & -.40 & & & & & & & & \\
\hline 5. Number of author & 1.90 & 1.12 & .14 & .26 & -.32 & .27 & & & & & & & \\
\hline 6. Affiliation rank & 198.90 & 179.52 & .09 & .06 & .07 & .01 & -.05 & & & & & & \\
\hline 7. Agg. Impact factor field & 1.41 & .40 & .20 & .30 & -.35 & .31 & .40 & -.08 & & & & & \\
\hline 8. Impact factor journal & 2.60 & 2.00 & .49 & .60 & -.16 & .39 & .34 & .05 & .45 & & & & \\
\hline 9. Quant. Article & .41 & .49 & .01 & .06 & -.27 & .02 & .48 & -.02 & .39 & .24 & & & \\
\hline 10. Qual. Article & .32 & .47 & -.22 & -.28 & .05 & -.14 & -.37 & .01 & -.46 & -.38 & -.57 & & \\
\hline 11. Theory Article & .24 & .43 & .23 & .18 & .30 & .03 & -.19 & -.01 & .02 & .12 & -.46 & -.39 & \\
\hline 12. Review Article & .03 & .18 & .02 & .13 & -.10 & .24 & .11 & .06 & .06 & .04 & -.15 & -.13 & -.10 \\
\hline
\end{tabular}

Note: times cited as of 6 April 2015. 
Figure 1A: The intellectual landscape of the socio-scientific study of charisma

Note: Full document co-citation network. Figure 1B shows the top half-percent most co-cited works within this network. 


\section{Figure 1B: The intellectual landscape of the socio-scientific study of charisma}

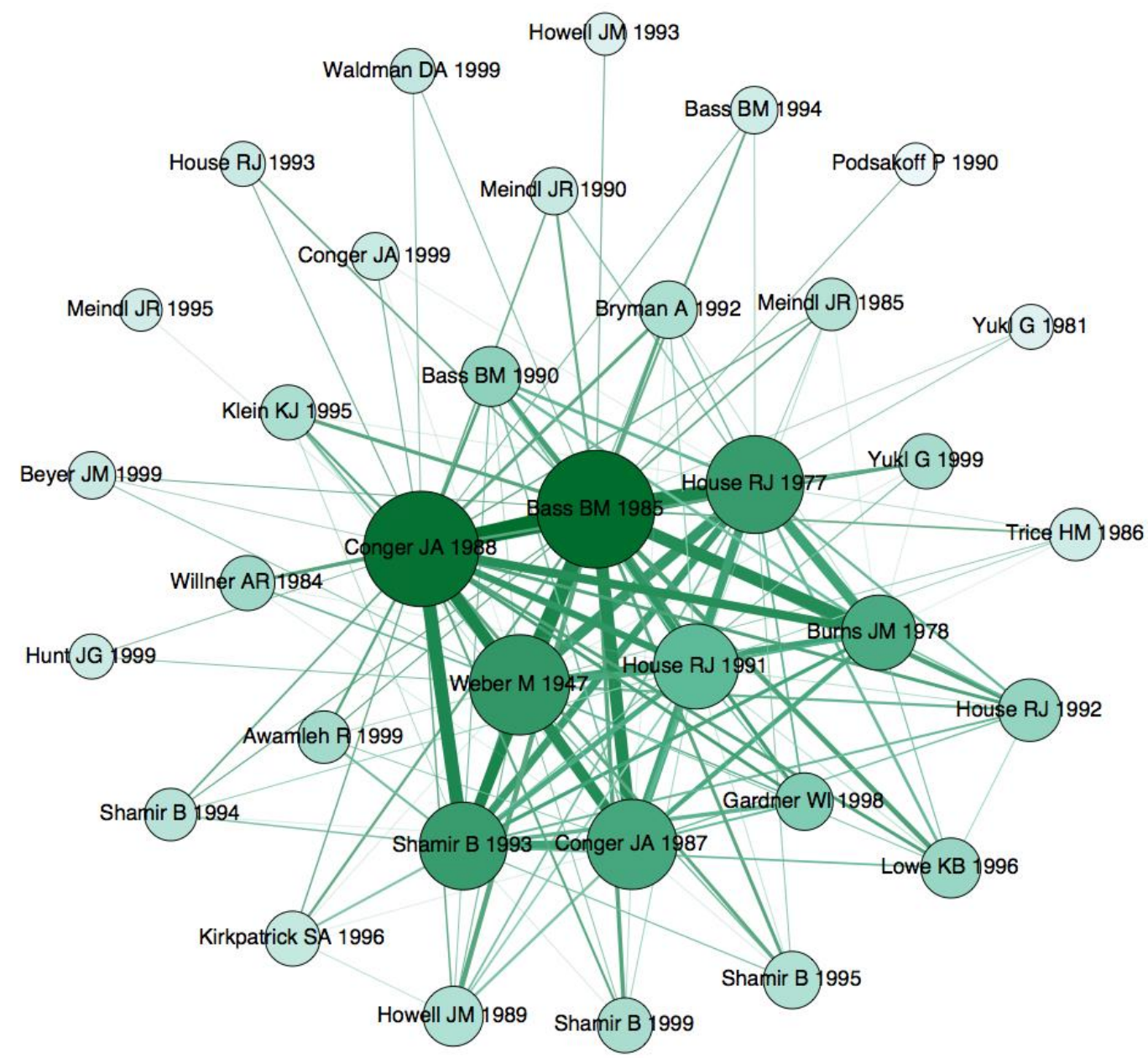

Note: Document co-citation network showing only the $0.5 \%$ most co-cited works. Each node represents one document (only first authors are named) and edges represent the co-citations of two documents. Darker and thicker edges indicate more co-citations. Node size indicates the number of other documents with which this node is co-cited (degree), and its color indicates the sum of the weights of all edges to which this node is connected to (strength) - darker color indicates greater strength. 
Figure 2: Source co-citation analysis of the socio-scientific study of charisma

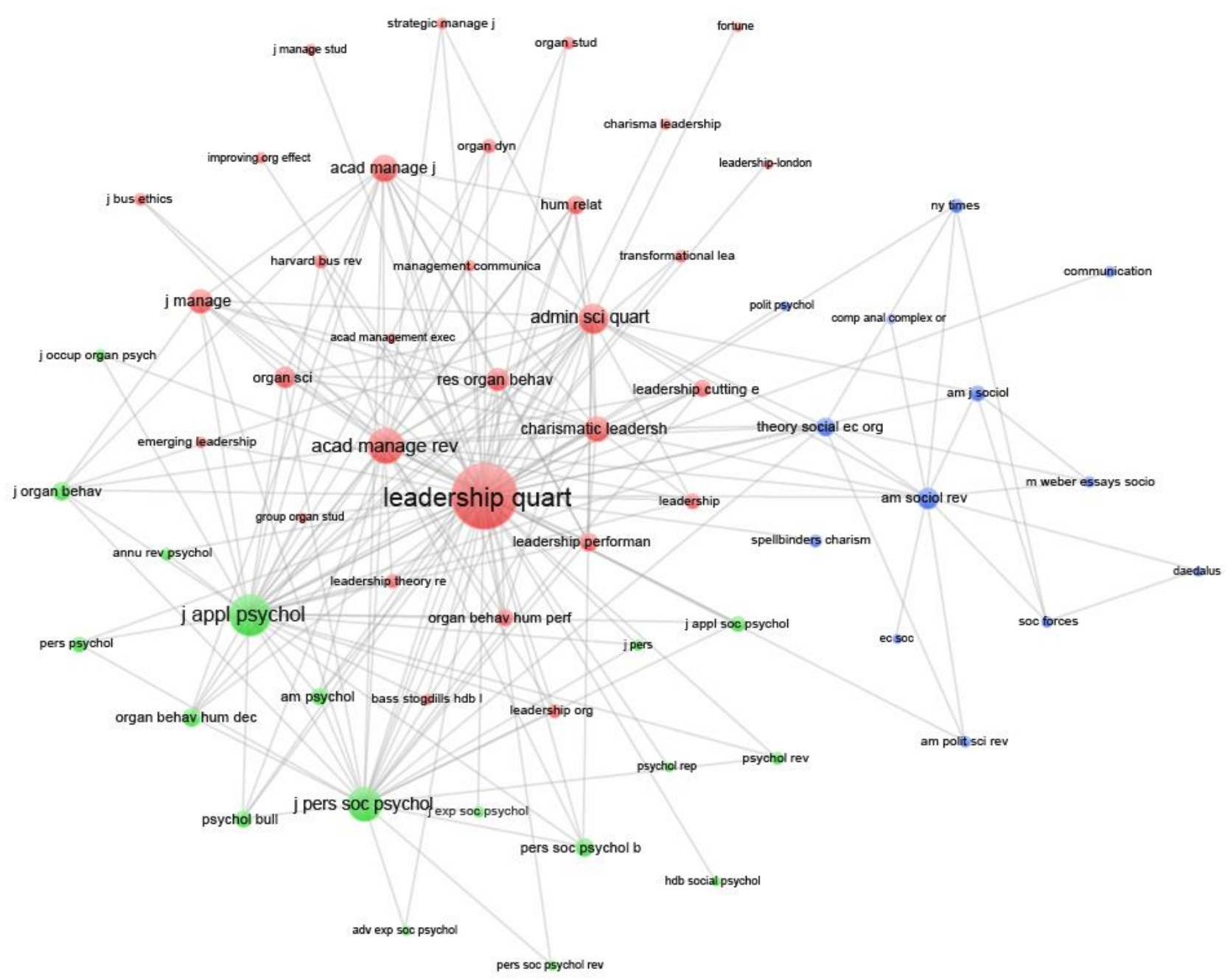

Note: Difference in node size indicates relative difference in the frequency of occurrence. Sources that are frequently co-cited are positioned close to each other. The 200 strongest edges are represented. Node color indicates membership to a common densely connected cluster, as identified by an algorithm. The blue cluster contains sociology and political sources, the red cluster contains management sources, and the green cluster contains psychology sources. 


\section{References:}

Aksnes DW. 2003. Characteristics of highly cited papers. Research Evaluation 12: 159-70

Antonakis J, Bastardoz N, Liu Y, Schriesheim CA. 2014. What makes articles highly cited? The Leadership Quarterly 25: 152-79

Antonakis J, Lalive R. 2008. Quantifying scholarly impact: IQp versus the Hirsch h. Journal of the American Society for Information Science and Technology 59: 956-69

Avolio BJ, Bass BM, Jung DI. 1995. MLQ Multifactor leadership questionnaire: Technical Report. Redwood City, CA: Mindgarden

Bergh DD, Perry J, Hanke R. 2006. Some predictors of SMJ article impact. Strategic Management Journal 27: 81-100

Blevins DP, Tsang EWK, Spain SM. 2015. Count-Based Research in Management: Suggestions for Improvement. Organizational Research Methods 18: 47-69

Conger JA, Kanungo RN. 1998. Charismatic leadership in organizations. Thousand Oaks, CA: Sage Publications.

Cox DR, Snell EJ. 1989. Analysis of binary data. London ; New York: Chapman and Hall. vii, 236 p. pp.

De Hoogh A, Den Hartog D, Koopman P. 2004. De ontwikkeling van de CLIO: een vragenlijst voor charismatisch leiderschap in organisaties. Gedrag en Organisatie 17: 354-81

Huber PJ. 1964. Robust estimation of a location parameter. Annals of Mathematical Statistics 35: 73-101

Landis JR, Koch GG. 1977. The measurement of observer agreement for categorical data. Biometrics 33: 159-74

Larivière V, Gingras Y. 2010. The impact factor's Matthew Effect: A natural experiment in bibliometrics. Journal of the American Society for Information Science and Technology 61: 424-27

Lokker C, McKibbon KA, McKinlay RJ, Wilczynski NL, Haynes RB. 2008. Prediction of citation counts for clinical articles at two years using data available within three weeks of publication: retrospective cohort study. BMJ 336: 655-57

Podsakoff PM, MacKenzie SB, Moorman RH, Fetter R. 1990. Transformational leader behaviors and their effects on follower's trust in leader, satisfaction, and organizational citizenship behaviors. The Leadership Quarterly 1: 107-42

Sci2 Team. 2009. Science of Science (Sci2) Tool. Indiana University and SciTech Strategies: https://sci2.cns.iu.edu

Van Eck NJ, Waltman L. 2010. Software survey: VOSviewer, a computer program for bibliometric mapping. Scientometrics 84: 523-38 